\title{
DERECHO A LA CIENCIA. LIBERTAD DE INVESTIGACIÓN, ACCESO, PARTICIPACIÓN Y PROMOCIÓN DE LA CIENCIA EN EL ORDENAMIENTO ESPAÑOL
}

\author{
RIGHT TO SCIENCE. \\ FREEDOM OF RESEARCH, ACCESS, \\ PARTICIPATION AND PROMOTION OF SCIENCE \\ IN THE SPANISH LEGAL SYSTEM
}

\author{
DaVid VILA-Viñas \\ Universidad de Zaragoza
}

Fecha de recepción: 19-3-20

Fecha de aceptación: 1-9-20

Resumen: El derecho a la ciencia está reconocido en normas internacionales y constitucionales, como la Constitución Española de 1978. En este artículo se discute la configuración de la ciencia como su objeto, su consideración como un bien común y los valores que constituyen el fundamento de este derecho. Se distinguen tres dimensiones de este derecho para realizar un análisis de su contenido y los principales riesgos de vulneración. Estas son, la libertad de investigación científica (artículo 20.1.b Constitución Española) el derecho de acceso a la ciencia y al disfrute de sus beneficios (artículo 15 del Pacto Internacional de Derechos Económicos, Sociales y Culturales) y el derecho a disfrutar de una actividad promocional de la ciencia por parte del Estado (artículo 44.2 CE).

Abstract: The right to science is recognized in international and constitutional norms, such as the Spanish Constitution of 1978. This article discusses the configuration of science as its object, its consideration as a common and the values in which that right is founded. Three dimensions of this right are distinguished in order to make an analysis of its content and the main risks of violation. These are the freedom of scientific research (Article 20.1.b of the Spanish Constitution), the right of access to science and the enjoyment of its benefits (Article 15 of the International Covenant on Economic, Social and Cultural Rights) and the right to enjoy the promotion of science by the State (Article 44.2 EC).

ISSN: $1133-0937$

DOI: https://doi.org/10.20318/dyl.2021.6110
DERECHOS Y LIBERTADES

Número 45, Época II, junio 2021, pp. 327-364 
Palabras clave: derecho a la ciencia, I+D, derechos humanos, derechos sociales, políticas de conocimiento

Keywords: $\quad$ right to science, $R \& D$, human rights, social rights, knowledge policies

\section{INTRODUCCIÓN}

En la etapa que se abrió con el final de la II Guerra Mundial, la libertad de investigación científica se reconoció como derecho en los principales instrumentos internacionales de derechos humanos y en las constituciones nacionales de posguerra, así como en la Constitución Española de 1978 (en adelante, CE). En el fundamento axiológico de esta libertad se sitúa el vínculo entre el libre desarrollo de la investigación científica y el disfrute de sus resultados, por una parte, y las nociones de dignidad, libre desarrollo de la personalidad y bienestar material, por otra. A pesar de contar con un sustrato de valores compartidos por otros derechos, aquel resulta singular sobre todo a causa de su objeto. En este artículo se considerará la ciencia como un bien común definido formalmente por la acción horizontal de la comunidad científica. La libertad de investigación científica también es singular en cuanto al carácter necesariamente institucional y colectivo de su efectuación, ya que, solo en el contexto de esa comunidad científica libre, cabe desarrollar una producción de conocimiento coherente con este derecho. A partir de dicha caracterización inicial, el artículo se centrará en distinguir tres dimensiones del derecho a la ciencia. Aunque se trata de aspectos indivisibles para la efectividad del derecho, se ordenarán de este modo porque cada uno de ellos cuenta con unas especificidades, en cuanto a su conceptuación y operatividad. No en vano se van a identificar positivaciones concretas de cada uno de ellos. Se trata de la dimensión de libertad de actividad científica (artículo 20.1.b CE), del derecho de acceso a la actividad científica y el disfrute de sus beneficios (artículo 15 del Pacto Internacional de Derechos Económicos, Sociales y Culturales; en adelante, PIDESC) y del derecho a disfrutar de una actividad promocional de la ciencia por parte del Estado (artículo 44.2 CE). Para cada una de estas dimensiones y conforme al enfoque de las vulneraciones de derechos, se explorarán los aspectos conceptuales más influyentes en su efectividad, ligados a la realidad de la actividad investigadora y a sus implicaciones para las obligaciones negativas y positivas del Estado, en especial en el contexto español. Todo ello, a partir de la premisa de que conceptuar mejor las es- 
trechas interrelaciones entre las diferentes dimensiones de este derecho es imprescindible para poder diseñar unas garantías eficaces.

\section{CIENCIA. CONCEPTOS, VALORES Y PRINCIPIOS POLÍTICOS SUBYACENTES}

\subsection{La problemática delimitación jurídica del objeto científico}

Aunque los instrumentos internacionales de reconocimiento de derechos han incorporado desde hace casi ochenta años referencias a distintos aspectos de un denominado derecho a la ciencia, a su libre producción y al disfrute de sus beneficios, la denominación de este derecho no ha dejado de ser una cuestión abierta. En términos globales, se entiende que esta noción contiene los aspectos relativos a las libertades ideológicas, de expresión e información ${ }^{1} \mathrm{y}$ al derecho a "gozar de los beneficios del progreso científico y de sus aplicaciones" ${ }^{2}$. Al mismo tiempo, se trata de una noción expresiva y fácil de comunicar al conjunto de la ciudadanía ${ }^{3}$, lo que supone un activo en la esfera comunicativo-política, relevante en último término para la efectividad de los derechos ${ }^{4}$. Es cierto, no obstante, que la noción que se constitucionaliza con mayor peso en el ordenamiento español es la de libertad de investigación científica (artículo 20.1.b CE). Aunque conceptualmente sería posible incluir las distintas dimensiones del derecho a la ciencia bajo aquella noción de libertad, resulta lógico acudir a un término más amplio y expresivo, tanto por la heterogeneidad de los contenidos de este derecho como por su mayor correspondencia con la denominación de la doctrina internacional.

1 Cabría deducir esta dimensión del derecho de los artículos 18 y 19.2 del Pacto Internacional de Derechos Civiles y Políticos, de 1966 (en adelante, PIDCP) y del artículo 15.3 PIDESC. Vid. infra secc. 3.1.

2 Tal es la formulación del artículo 15.1.b) del PIDESC. Vid. infra secc. 3.2.

3 L. SHAVER, "The Right to Science: Ensuring that Everyone Benefits from Scientific and Technological Progress", European Journal of Human Rights, núm. 4, 2015, pp. 411-443 (https://doi.org/10.2139/ssrn.2564222).

4 M. CALVO GARCÍA, "Derechos sociales : algunas propuestas para seguir avanzando en tiempos de incertidumbre" en M. ABAD CASTELOS et al. (eds.), Políticas económicas $y$ derechos sociales, Robinson, Madrid, 2016, pp. 163 y ss. Ver también C. RODRÍGUEZWANGÜEMERT y J. MARTÍNEZ-TORVISCO, "Human lights through the paradigm changes of the social communication theories", International Review of Sociology, núm. 27 vol. 2, 2017, pp. 230-240, (https://doi.org/https://doi.org/10.1080/03906701.2017.132900). 
La segunda cuestión a dilucidar respecto a este derecho es el objeto ciencia a que se refiere. Cuando se alude a un conjunto tan complejo como es, al menos, el conocimiento válido en un determinado momento histórico y las reglas comúnmente asumidas para su validación ${ }^{5}$, parece razonable que el derecho pueda tener sus reservas a la hora de ofrecer una definición de su objeto. Nótese que, desde un enfoque positivista, las elementos de la ciencia jurídica, y con ello las reglas relativas a la determinación de sus objetos, forman parte del ámbito de la ciencia que se pretende delimitar. De este modo, la solución jurídica más prudente, ya que es imposible escapar de la necesidad de hacer operativa alguna suerte de definición, sería devolver la cuestión al ámbito científico, a través de una tautología del estilo "desde una perspectiva jurídica, ciencia será lo que el método científico defina como ciencia" ${ }^{\prime}$. Aparte de su pragmatismo, la ventaja de este enfoque es que maximiza la autonomía del ámbito científico frente a las injerencias de otros ámbitos; cuestión nada menor ya que, como se verá, forma parte del contenido esencial de la libertad de investigación científica:

La Ciencia sólo puede prosperar en un clima de libertad. Y este clima de libertad no depende únicamente de una libertad externa, es decir, de su independencia respecto a cualquier tipo de influencia política, sino también de que exista libertad dentro de la Ciencia (...), ya que el alma de la Ciencia es la tolerancia ${ }^{7}$.

Este enfoque, que podría denominarse como una definición formal de la ciencia por parte del derecho, es el que abraza la propia Ley española 14/2011, de 1 junio, de la Ciencia, la Tecnología y la Innovación cuando, en su artículo 13.1, define la actividad investigadora "como el trabajo creativo realizado de forma sistemática para incrementar el volumen de conocimientos, incluidos los relativos al ser humano, la cultura y la sociedad, el uso de esos conoci-

5 Véase A. R. CHAPMAN, "Towards an Understanding of the Right to Enjoy the Benefits of Scientific Progress and its Application", Journal of Human Rights, núm. 8, 2009, pp. 6 y ss, respecto al contexto político-sociológico mertoniano en que se definió la ciencia como objeto de este derecho en el periodo posterior a la II Guerra Mundial.

6 M. A. AHUMADA CANABES, "La libertad de investigación científica: Panorama de su situación en el constitucionalismo comparado y en el Derecho Internacional", Revista chilena de derecho, núm. 39 vol. 2, 2012, pp. 411-445 defendería, a partir de una argumentación más completa, una posición análoga a ésta.

7 H. KELSEN, ¿Qué es justicia?, A. CALSAMIGLIA (ed.), Ariel, $3^{\text {a }}$ ed., Barcelona, 1992, p. 62. 
mientos para crear nuevas aplicaciones, su transferencia y su divulgación" 8 . También es el enfoque al que se adhiere el Tribunal Constitucional (el adelante, TC) cuando indica que el objeto ciencia no lo determina el derecho, sino más bien los estándares científicos de cada momento ${ }^{9} \mathrm{o}$ cuando, al tener que resolver conflictos entre este derecho y el de honor, intimidad y propia imagen, incide en que la condición para acceder a la tutela del primero es ser fiel a un método concreto y riguroso de investigación ${ }^{10}$.

En este punto la cuestión es si dicha remisión al método científico se corresponde con la pura abstención de la acción jurídico-política para dejar paso a la de una ciencia autónoma o si, como postulan los enfoques sobre la gubermentalidad $^{11}$, aquella acción pública es indispensable no solo para tutelar, sino también para producir, dicha autonomía científica. Al caracterizar la gubermentalidad liberal, Michel Foucault describió bien cómo, en su interior, libertad no se contraponía a un estado de naturaleza, carente de normas e instituciones. Al contrario, un objetivo principal de la acción de gobierno

8 Como bien señalada M. M. DARNACULLETA I GARDELLA, "Libertad de investigación científica y la promoción de la ciencia en beneficio del interés general" en F. LÓPEZ RAMÓN et al. (eds.), Organización de la Universidad y la Ciencia, INAP. Madrid 2018, p. 14 (http://www.aepda.es/AEPDAPublicaciones-1876-Actividades-Congresos-de-la-AEPDA-XIIICONGRESO-DE-LA-AEPDA.aspx), se incorpora así la definición de la OCDE, como se sigue constatando en el Manual Frascati, OCDE, 2015, cap. 2 y como previamente había sostenido la doctrina jurídica alemana en pos de la autonomía del ámbito científico.

9 Véase la STC 43/2004, en su FJ 8, así como el análisis de G. ARRUEGO RODRÍGUEZ, “El derecho fundamental a la investigación científica en la Constitución Española de 1978” en R. L. CHUECA (ed.), La investigación científica como derecho fundamental, Comares, Granada, 2012, p. 53.

10 Véanse las SSTC 43/2004, FFJ 4 y 5, y 214/1991, FJ 8, a propósito de la libertad de investigación en el ámbito historiográfico, notando que, como indica ARRUEGO, "El derecho fundamental a la investigación científica en la Constitución Española de 1978", cit. pp. 54 y 55, el enfoque formal y la relevancia del método no es incompatible con que este derecho incluya la protección de la subjetividad del investigador y de su producción como un acto creativo, expresado incluso a través de métodos heterodoxos, siempre que se encuentren bien fundados.

11 Para ampliar esta noción, véanse, entre muchas referencias, M. DEAN, Governmentality: Power and rule in modern society, Sage, London, 2003, M. VALVERDE, "Specters of Foucault in law and society scholarship", Annual Review of Law and Social Science, núm. 6, 2010, pp. 45-59 y D. VILA-VIÑAS, “El pensamiento jurídico de los 'Estudios de Gubernamentalidad'. Los desarrollos post-foucaultianos acerca del funcionamiento del poder desde una perspectiva jurídica", Anuario de Filosofía Jurídica, núm 29, 2013, pp. 493-513. 
es producir la libertad ${ }^{12}$, esto es, el marco normativo e institucional que no regula la actividad dada en un sentido restrictivo, sino que la delimita, en un sentido creativo: menos reglamentar los procesos sociales que gobernarlos conforme a un conjunto de normas formuladas en su interior, de acuerdo con su propio funcionamiento en el medio ${ }^{13}$. Desde este enfoque, el rol de la norma sería en primer lugar de carácter epistémico: se situaría en un campo homogéneo de datos positivos o de elementos fácticos que requieren estandarización para hacer posible ahí una labor de objetivación o categorización. Así, normar no es solo dar reglas, sino objetivar el campo de validez y eficacia de las prácticas de un determinado sector, a través de la configuración de un conjunto de categorías, taxonomías, técnicas, etc ${ }^{14} \cdot y$, por supuesto, delimitar con ello un campo exterior a la norma a través de una serie de tecnologías de discriminación que, en este caso, permitirán identificar lo impropio del campo científico, lo que no debe ser tutelado por un derecho a la libertad científica.

De este modo, la remisión formal no funciona solo como una abstención, sino que exige una acción positiva de normación. A este enfoque se aproxima Chueca ${ }^{15}$ cuando señala que la ciencia moderna se delimita a partir de un proceso de normación, por el que la actividad científica existe con el método, instituciones y reglas actuales no como un ámbito autónomo, sino dentro del derecho, bajo el conjunto de normas jurídicas que establecen no solo este derecho fundamental a la libertad de investigación científica, sino sus objetivos, métodos, deontología y límites éticos. No se trataría por lo tanto del límite exterior a una actividad por lo demás autónoma, sino una condición interna para el propio rigor científico ${ }^{16}$. A partir de este suelo formalista, con-

12 Sobre la producción de libertad, véase D. VILA-VIÑAS, La gobernabilidad más allá de Foucault. Un marco para la teoría social y política contemporáneas, Prensas Universitarias de Zaragoza, Zaragoza, 2014, pp. 69 y ss.

13 Véase M. FOUCAULT, Seguridad, territorio, población. Curso del Collège de France (19771978), Akal, Madrid, 2008, pp. 334 y 335 y J. GOODIE, “The invention of the environment as a subject of legal governance" en G. WICKHAM y G. PAVLICH (eds.), Rethinking Law, Society and Governance: Foucault's Bequest, Hart, Oxford, 2001, pp. 73-92.

14 Véase F. EWALD, “Norms, Discipline, and the Law”, Representations, núm. 30, 1990, p. 156.

15 Véase R. I. CHUECA RODRÍGUEZ “La investigación científica como espacio iusfundamental de normación” en R. I. CHUECA (ed.), La investigación científica como derecho fundamental, cit. p. 28, donde señala la conversión de la ciencia en una actividad transitiva.

16 "[P]odemos seguir afirmando que el conocimiento hace libre en la medida en que nos permite conocer el mundo en el que nos desenvolvemos vitalmente. Pero esta libertad 
viene señalar también que es necesario encontrar la fórmula para dar traslado a estos conceptos de los valores económicos y sociales que ha adquirido la ciencia en el Estado Social y Democrático de Derecho y en virtud de la cual no puede reducirse a una libertad de carácter individual e interior ${ }^{17}$.

Tanto el inicial enfoque formal como esta última inflexión más material o transitiva encuentran asimismo algunas objeciones. En primer lugar, una crítica compartida por distintas perspectivas señala que la definición formal de la ciencia por parte del derecho es más un ideal o una ficción que una descripción. Tal como ocurre en el positivismo jurídico, tras la formalidad de la normación científica, descansa una determinada visión de la ciencia y sus formas de capital ${ }^{18}$, propia de personas bien posicionadas en la misma. De esta manera, lo razonable, lo propio de un espíritu científico genuino sería precisamente cuestionar la neutralidad y el carácter aséptico de ese enfoque y problematizar en cambio el carácter político y social de sus prácticas ${ }^{19}$, así como su propuesta axiológica. En contraste con todo ello, una perspectiva material o transitiva sí se propondría evidenciar ese sustrato y esos objetivos.

Este giro no resulta, sin embargo, suficiente para algunas perspectivas críticas que identifican un exceso de normación y, más allá, de intervención por parte del Estado. Así, el espacio de autonomía científica se ve condicionado, en primer lugar, por la definición de una serie de objetivos y valores por parte de las normas jurídicas, siquiera sean internacionales o de alto rango y, en segundo lugar, por la concreción gubernativa de estos principios y objetivos en determinados parámetros cienciométricos, bibliométricos y de evaluación de la actividad investigadora ${ }^{20}$. Aunque en la sección 3.1 se reto-

no es ya, si alguna vez lo fue, una libertad más allá del derecho. Todo lo contrario, la libertad de investigación científica exige hoy la inserción de su contenido jurídico preciso en los mismos fundamentos de los ordenamientos constitucionales. Y anuncia ya una poderosa tendencia a generalizar estándares supraestatales" CHUECA, La investigación científica como derecho fundamental,cit. p. 29.

17 Véase CHUECA, La investigación científica como derecho fundamental, cit. p. 34.

18 Véase P. BOURDIEU “Las formas del capital. Capital económico, capital cultural y capital social" en A. GARCÍA INDA (ed.), Poder, derecho y clases sociales, Desclée de Brouwer, Bilbao, 2001, pp. 131-164.

19 Véase B. LATOUR, Nunca hemos sido modernos: ensayo de antropología simétrica, Debate, Barcelona, 1993, entre otros estudios clave de ciencia, tecnología y sociedad, para ampliar estos enfoques.

20 Véase DARNACULLETA I GARDELLA, “Libertad de investigación científica y la promoción de la ciencia en beneficio del interés general", cit. pp. 13 y ss, que señala como ejemplo de esto el sistema de acreditaciones o de reconocimiento de sexenios, así como, 
mará este debate a propósito de las obligaciones que supone para el Estado el reconocimiento de esta libertad de investigación científica, el problema de pretender que el contenido de esta libertad no esté adscrito a ninguna concepción de la ciencia es que, contra la intuición inicial de estar ampliando su alcance, se estaría dejando el derecho en una situación de mayor incertidumbre y perjudicando con ello su eficacia. En la medida en que esta libertad entra en frecuente conflicto con otras y cuenta con vulnerabilidades notables, como se verá en la siguiente sección, la definición de unas reglas metodológicas que delimiten la investigación científica ofrece a quien la realiza o pretende realizarla más garantías de efectividad de este derecho. Eso sí, a condición de que tal definición sea falsable y abierta a uno de los valores superiores de nuestro ordenamiento jurídico, como es la pluralidad. Es decir, de que se trate de un concepto de ciencia abierto a otras expresiones de la subjetividad de quienes investigan, siquiera sean heterodoxas, siempre que se encuentren bien fundadas ${ }^{21}$. Por otro lado, si la discusión se centra en qué tipo de investigación científica debe promover el Estado, en virtud de las obligaciones derivadas de la formulación más económico-social de este derecho, como la que se hace en el artículo $44.2 \mathrm{CE}^{22}$, tal previsión es coherente con el principio democrático de que sea la dirección política del Estado la que establezca y promueva esos objetivos prioritarios, siempre que estos sean coherentes con

desde una perspectiva foucaultiana, P. AMIGOT LEACHE y L. MARTÍNEZ SORDONI, "Gubernamentalidad neoliberal, subjetividad y transformación de la universidad. La evaluación del profesorado como técnica de normalización”, Athenea Digital, núm. 13 vol. 1, 2013, pp. 99-120.

21 Nótese que, aunque en el ámbito estatal el principio de pluralidad opera sobre todo como una garantía frente a la imposición o apoyo exclusivo a una perspectiva científica por parte del Estado, en la escala internacional este valor pretende garantizar la protección de los conocimientos, innovaciones y prácticas creativas de comunidades indígenas o locales. Véase, en este sentido, la Observación General N 17, de 21 de noviembre de 2005, del Comité de Derechos Económicos, Sociales y Culturales (E/C.12/GC/17. Disponible en http://portal. unesco.org/culture/es/files/30545/11432108781Comment_sp.pdf/Comment_sp.pdf), apartado II.9, en su interpretación del artículo 15.c del PIDESC. Para una perspectiva postcolonial sobre las políticas de reconocimiento de saberes comunitarios véase J. M. CRESPO y D. VILAVIÑAS, "Comunidades: Saberes y conocimientos originarios, tradicionales y populares", en D. VILA-VIÑAS y X. E. BARANDIARAN (eds.), Buen Conocer - FLOK Society. Modelos sostenibles y políticas públicas para una economía social del conocimiento común y abierto en el Ecuador, IAEN - CIESPAL, 2015, pp. 619-691 (http://book.floksociety.org/ec/3/3-2-comunidades-saberes-yconocimientos-originarios-tradicionales-y-populares) y, de manera más general, sobre las relaciones científicas, T. TUCKER y M. W. MAKGOBA, "Public-Private Partnerships and Scientific Imperialism", Science, núm. 320, 2008, pp. 1016-1017.

22 Vid. infra secc. 3.3.

DERECHOS Y LIBERTADES

ISSN: 1133-0937

Número 45, Época II, junio 2021, pp. 327-364

DOI: https://doi.org/10.20318/dyl.2021.6110 
la propia racionalidad científica, que incluye un criterio de apertura también política, y el principio de pluralismo al que se ha aludido.

En todo caso, introducir dos desplazamientos de este problema puede ayudar a enfocarlo mejor para hacer más eficaz este derecho frente a los riesgos actuales. En primer lugar, delimitada la ficción sobre la vacua formalidad de la ciencia, sí sería legítimo y recomendable identificar y debatir sobre los objetivos y los valores que subyacen a las distintas propuestas científicas, como se tratará de hacer a continuación. No conviene olvidar que avance científico e interés general no son necesariamente idénticos y que, ante eventuales bifurcaciones, la protección de la libertad de investigación abarca solo a aquella compatible con el conjunto de los principios constitucionales. En segundo lugar, una de las premisas de este artículo es que, al considerar las vulneraciones al derecho a la ciencia, ha sido habitual desconocer el impacto de la retracción o la ausencia de una acción pública de fomento de esta actividad cuando, al menos en el contexto español, su impacto es al menos equiparable al de las tradicionales injerencias o condicionamientos del Estado respecto a la actividad científica. Documentar mediante las investigaciones socio-jurídicas pertinentes esta observación ofrecería una nueva mirada sobre los riesgos actuales a las libertades y permitiría diseñar garantías más eficaces para este derecho.

\subsection{La ciencia, un común plural}

En este apartado se expondrán los contenidos axiológicos que subyacen al derecho a la ciencia y se formularán algunas propuestas para caracterizar ésta desde una perspectiva político-filosófica, axiológica e iusfundamental, tal como se introdujo durante el apartado anterior.

En la tarea de fundamentar este derecho, ha sido habitual recurrir a su finalidad, a su impacto en la mejora de las condiciones de vida y con ello en la efectividad de otros muchos derechos, como el acceso a medicinas, a bienes de primera necesidad, tales como el agua y los saneamientos, o a las comunicaciones y a la movilidad. De este modo, cierto nivel de desarrollo científico se convierte en una condición para el disfrute de ciertos derechos fundamentales, así como para avanzar en la conformación de unas personas y comunidades más capaces de resolver sus problemas materiales. Sin embargo, al igual que ocurre con el derecho a la educación, resulta polémico que su fundamento se sustente solo en una racionalidad instrumental. En cambio, cabe 
argumentar que la libertad de investigación científica y el derecho a acceder a ésta contienen un valor en sí mismas, un valor vinculado a la dignidad de la persona ${ }^{23}$ y a las nociones ilustradas de emancipación y acceso a la autonomía personal ${ }^{24}$. Por supuesto no cualquier práctica científica encaja con esta concepción. El enfoque de derechos humanos acota la ciencia susceptible de tutela a aquella que se dispone "al servicio de la humanidad" 25 , que se dedica a la mejora de las condiciones de vida y al alivio del sufrimiento, conforme a unos estrictos parámetros éticos ${ }^{26}$. Aunque la propia pluralidad de las nociones de dignidad que avala nuestro ordenamiento pueda dificultar la concreción de este enfoque ${ }^{27}$, se trata de un fundamento consolidado de este derecho.

A partir de este sustrato axiológico y de la consiguiente proyección estratégica del derecho a la ciencia, cobra sentido considerar a la misma como un bien público o bien común, según la perspectiva ${ }^{28}$ :

23 Véase, en apoyo de esta perspectiva, SHAVER, “The Right to Science: Ensuring that Everyone Benefits from Scientific and Technological Progress", cit. pp 415 y 416, así como ARRUEGO, "El derecho fundamental a la investigación científica en la Constitución Española de 1978 ", cit. p. 51 sobre el vínculo de esta libertad con el derecho fundamental a la dignidad de la persona.

24 Sobre la racionalidad filosófico-política que comprenden los valores ilustrados en esta dirección, véase M. FOUCAULT, “¿Qué es la Ilustración?” en S. MATTONI (ed.), Alcián, Buenos Aires, 2002.

${ }_{25}$ Véase SHAVER "The Right to Science: Ensuring that Everyone Benefits from Scientific and Technological Progress", cit., p. 416.

26 Nótese que estos también son algunos de los criterios hermenéuticos con los que dirimir los conflictos que puedan producirse con otros derechos.

27 CHAPMAN, "Towards an Understanding of the Right to Enjoy the Benefits of Scientific Progress and its Application", cit., pp. 11 y 12 señala al menos dos concepciones de la dignidad habituales y conflictivas en este ámbito. En primer lugar, la que se vincula a la capacidad, sobre todo individual, de adoptar decisiones autónomas y que se sintetizaría en el empoderamiento y en la capacidad de prestar consentimiento informado y libre respecto a asuntos científicos. En segundo lugar, una de carácter limitativo, vinculada a la necesidad de conservar un núcleo de la comprensión de lo humano frente a nuevas propuestas científicas y que suele ser relevante en ámbitos como la genética.

28 Aunque en el ámbito jurídico está más extendida la noción de bien público, como muestran AHUMADA, “La libertad de investigación científica: Panorama de su situación en el constitucionalismo comparado y en el Derecho Internacional”, cit. o SHAVER, "The Right to Science: Ensuring that Everyone Benefits from Scientific and Technological Progress", cit., en el ámbito sociológico, económico y politológico lo está más la de bien común o commons, debido a la influencia de E. ÖSTROM, Governing the commons: The evolution of institutions for collective action. Cambridge, M.A., Cambridge University Press, 1990 y E. ÖSTROM y C. HESS (eds.), Los bienes comunes del conocimiento, Madrid, Traficantes de Sueños, IAEN, 2016. Desde 
El conocimiento científico tiene las propiedades necesarias para ser considerado como un bien público, lo que justificaría su extracción del mercado y su no privatización. Al igual que los bienes públicos, se caracteriza por la no rivalidad y la no exclusividad, es decir, porque cualquier persona puede hacer uso del conocimiento, sin que ello afecte a los demás y porque los beneficios que de él derivan están disponibles para todos ${ }^{29}$.

Distinciones conceptuales aparte, esta consideración ofrece algunas ventajas respecto al objetivo de aumentar la eficacia de este derecho. La primera reside en que no solo da importancia a la producción de una libertad de investigación y a su defensa frente a injerencias externas, sino que introduce dentro de sus contenidos el acceso, tanto a la actividad científica en sí como a sus resultados. Es decir, resulta más coherente con la conceptuación multidimensional de este derecho a la ciencia. En segundo lugar, en la medida en que dicha consideración como bien común constituye más un horizonte estratégico del gobierno del conocimiento que una caracterización necesaria en el presente, aquella anticipa la orientación de las políticas públicas en la materia: garantizar el acceso, desmercantilizar el bien y asegurar la participación democrática en su funcionamiento, en especial de las poblaciones más vulnerables ${ }^{30}$. Esto incluye también la implementación de medidas de divulgación masiva de los procesos y resultados científicos a través de plataformas de publicación abierta y de las metodologías colaborativas y descentralizadas de producción de conocimiento científico ${ }^{31}$.

el ámbito juridico pero conforme al enfoque de los bienes comunes del conocimiento, veáse M. ORTIZ GARCÍA, "Reflexiones sobre la generación digital-colaborativa del conocimiento y su transferencia de bien común desde la universidad" en F. LÓPEZ RAMÓN et al. (eds.), Organización de la Universidad y la Ciencia, cit. pp. 445-459. Aunque en muchos discursos operen como sinónimos, la noción de comunes incluye la distinción entre la titularidad pública y la consiguiente gestión por parte de las administraciones y la titularidad del común y una gestión por lo tanto más directa por parte de la ciudadanía o de un grupo social dado.

29 AHUMADA, "La libertad de investigación científica: Panorama de su situación en el constitucionalismo comparado y en el Derecho Internacional”, cit., p. 428.

30 Véase el programa de SHAVER, "The Right to Science: Ensuring that Everyone Benefits from Scientific and Technological Progress", cit. p. 413 para la efectividad de este derecho.

31 Véase, en esta dirección la caracterización de M. ORTIZ GARCÍA "Reflexiones sobre la generación digital-colaborativa del conocimiento y su transferencia de bien común desde la universidad", cit. y las propuestas de X. E. BARANDIARAN et al., "Ciencia: investigación participativa, colaborativa y abierta", en D. VILA-VIÑAS (eds.), Buen Conocer - FLOK Society. Modelos sostenibles y políticas públicas para una economía so-

ISSN: 1133-0937

DOI: https://doi.org/10.20318/dyl.2021.6110
DERECHOS Y LIBERTADES

Número 45, Época II, junio 2021, pp. 327-364 
En el otro extremo de la concepción de la ciencia como un bien común se sitúa su consideración como bien privado. Una ciencia concebida enteramente como un bien regido por las reglas exclusivas del mercado, con eventuales protecciones a la libertad de investigación pero sin promoción alguna por parte de los poderes públicos en favor de su expansión ni del acceso de las poblaciones más vulnerables. Desde la perspectiva expuesta, esta concepción es incompatible con la regulación constitucional e internacional del derecho. Sin embargo y sin alcanzar este límite, la ciencia no opera en la práctica como un bien común, sobre todo a causa de dos grandes procesos. El primero es la llamada mercantilización de la ciencia o del conocimiento, referido a la reinscripción de las prácticas científicas en los criterios del mercado ${ }^{32}$. La clave de este proceso no es si el conocimiento científico, en todo o en parte, se produce en el interior del sector privado o del público ${ }^{33}$, sino que, con independencia de quienes lo protagonicen, sí se encuentra bajo un mismo régimen de veridicción ${ }^{34}$, bajo unos mismos criterios para distinguir el conocimiento científicamente adecuado del inadecuado, que son en esencia los que operan en ese mercado específico. Nótese en todo caso que este proceso va más allá de las continuidades entre la gubermentalidad liberal y una definición formal de la ciencia que se mostraron $^{35}$, ya que, a partir de determinado punto, dicha racionalización resulta incompatible con la producción científica desde un enfoque de derechos, en lo que respecta a los valores, los criterios de validación y de sostenibilidad del medio científico implicados ${ }^{36}$. Como resultado de este proceso, la ciencia se encuentra hoy en una situación ambivalente, ya que el rol es-

cial del conocimiento común y abierto en el Ecuador, cit., pp. 143-222 (http://book.floksociety.org/ ec/1/1-2-ciencia-investigacion-colaborativa-participativa-y-abierta).

32 CHAPMAN, 2009 cit. pp. 8 y 9 realiza un sucinto recorrido por el cambio en la comprensión de la ciencia durante la segunda mitad del siglo XX y la recepción crítica que esto tuvo en sectores de la comunidad científica.

33 Por ejemplo, M. MAZZUCATO, The Entrepreneurial State: Debunking Public Vs. Private Sector Myths. Anthem Press, London, 2014 ya mostró que la investigación pública puede liderar la innovación científica y estar supeditada al tiempo a los objetivos de mercado.

34 Véase sobre este concepto M. FOUCAULT, Nacimiento de la biopolítica. Curso en el Collège de France (1978-1979), México D.F., FCE, 2007, p. 53.

35 Vid. supra secc. 2.1 y X. FERREIRO BAAMONDE, “Mercantilizacón y precarización del conocimiento: El proceso de Bolonia", en EDU-FACTORY et al. (eds.), La universidad en conflicto, Traficantes de Sueños., Madrid, 2010, pp. 120-1, que vincula la mercantilización a nuevos riesgos también para la autonomía universitaria y la libertad de cátedra.

36 Véase S. HOREL, Lobbytomía, L. SANCHO (trad.), Morata, Madrid, 2019. 
pecial que el conocimiento desempeña en la producción contemporánea ${ }^{37}$ hace que, por una parte, el conocimiento sea un objeto a proteger y promover, al tiempo que, por otra parte, se convierte en el centro de procesos de producción y validación principalmente regidos por una racionalidad ajena a los valores emancipatorios de la ciencia.

El segundo proceso que cortocircuita el funcionamiento de la ciencia como un bien común es la consolidación de una gubermentalidad basada en la austeridad ${ }^{38}$. La limitación de la inversión pública en este ámbito ${ }^{39}$, así como el conjunto de políticas que impiden que despegue la inversión en el sector privado ${ }^{40}$, y que llevan a que se mantenga en niveles muy inferiores a los de los Estados del entorno, limita en el contexto de este artículo las características esenciales de los bienes comunes. Limita la participación en la investigación científica, al afectar a la cantidad de profesionales ${ }^{41}$, pero también las actividades de divulgación. Del mismo modo afecta a la sostenibilidad de la ciencia, ya que, aunque el uso de los bienes comunes no excluye el uso por parte de otras personas, no se trata de bienes que se produzcan sin coste. Al contrario, los bienes comunes, incluido los basados en conocimiento, tienen requerimientos biosociales para su producción y sostenibi-

37 Y. MOULLIER-BOUTANG, Cognitive Capitalism. Polity Press, Cambridge, 2011, p. 86 define esta etapa como "capitalismo cognitivo", lo que "designa un sistema de acumulación cuyo principal objeto de acumulación está constituido por el conocimiento, que se convierte en la fuente principal de valor así como en el lugar principal del proceso de valorización".

38 Véase M. BLYTH, Austeridad. Historia de una idea peligrosa, Crítica, Barcelona, 2014, para profundizar sobre este concepto.

39 Si se toma como referencia el periodo central de la crisis de 2008 y el despegue posterior (2009-2016) se observa que la inversión pública en I+D en España descendió un 9,1\% durante ese periodo, mientras que la media de la UE-28 aumentaba un 27,4\% y la de países como Reino Unido un 39,3\% o un 12,5\% la de Italia (Fuente: INE y Eruostat).

40 En 2018, la proporción de la inversión interna en I+D asumida por el sector privado alcanzó el 49,5\% del total. Aunque esto marca una tendencia ascendente en la evolución española, se mantiene lejos de la UE (Fuente: INE). Para datos comparados de 2016, la intensidad de la inversión en I+D ejecutada por el sector privado respecto al PIB fue del 0,64\%, mientras que la de la UE alcanzó el 1,34\% del PIB, con el agravante de que la brecha, que en 2009 se había situado en una proporción del 0,72\% y 1,18\%, ha aumentado notablemente en los años posteriores (Fuente: R. XIFRÉ, La inversión en I+D y la innovación después de la crisis: sector público y sector privado, Cuadernos de información económica, Funcas, núm 265 (julio-agosto), 2017, p. 17.

41 Solo en 2018, con 225.000 investigadores/as, se ha llegado a recuperar el nivel de 2010 de investigadores/as en jornadas equivalentes a tiempo completo (en adelante, EJC). En los años valle de este periodo, como 2014, se llegaron a perder más de 20.000 investigadores/ as EJC (Fuente: INE).

ISSN: 1133-0937

DOI: https://doi.org/10.20318/dyl.2021.6110
DERECHOS Y LIBERTADES

Número 45, Época II, junio 2021, pp. 327-364 
lidad $^{42}$ que las estrategias de austeridad ponen en riesgo. En todo caso, lo que se hace evidente, a efectos del interés del presente artículo, es que ni la definición de la ciencia ni su caracterización como objeto de derechos es un asunto pacífico que pueda referirse solo a criterios formales. Al contrario, se trata de una definición basada en posiciones axiológicas y políticas. A lo largo de la siguiente sección, se expondrá el modo en que cierta concepción de la ciencia y de la libertad de investigación se ha positivizado en el derecho español y cuáles son sus implicaciones respecto a los valores subyacentes y a su efectividad.

\section{POSITIVACIÓN EN EL ORDENAMIENTO ESPAÑOL}

En el objetivo de dotar de efectividad a determinados valores, como en este caso son los que vinculan el derecho a la ciencia con la dignidad y el acceso a mayores cotas de autonomía y de bienestar material, la positivación es una estrategia indispensable, aunque no suponga una garantía absoluta de eficacia $^{43}$. La constitucionalización de determinados contenidos axiológicos y principios políticos, como los reseñados en la sección anterior, aunque no el único, es un instrumento privilegiado de esta estrategia. En primer lugar, permite atender al contenido multidimensional de este derecho, que se organizará aquí en tres dimensiones materiales: la libertad de investigación científica, el derecho a acceder a la ciencia y a sus beneficios y, por último, el de disfrutar de una actividad promocional de aquella. En segundo lugar, debido la posición jerárquica de la norma constitucional, las previsiones respecto a la ciencia pueden servir para proteger un enfoque prudencialista y garantista de los valores constitucionales respecto ciertos desarrollos científicos, que por su propia definición son dinámicos y rupturistas. El establecimiento de unos principios constitucionales claros a este respecto, dentro de la perspectiva de la normación creativa que se adoptó en la sección 2.1, lejos de restringir el desarrollo científico, sirve para garantizar su práctica, así como de base al desarrollo legislativo ulterior. Si estos principios constitucionales se

42 Véase C. VERCELLONE et al., D3. 1-Theoretical Framework on future knowledge-based economy, D-Cent project, 2014 (http://dcentproject.eu/wp-content/uploads/2014/04/D3.1Theoretical-framework-on-the-knowledge-based-economy-and-ICT-driven-collective-intelligence.pdf).

43 Véase CALVO GARCÍA, “Derechos sociales : algunas propuestas para seguir avanzando en tiempos de incertidumbre", cit. e Id., "Crisis económica y efectividad de los derechos sociales" en M. J. BERNUZ Y M. CALVO (eds.), La eficacia de los derechos sociales, Tirant lo Blanch, Valencia, 2013, pp. 89-132. 
formulan además de manera flexible y abierta, su objetivo garantista podrá adaptarse a los nuevos contextos científico-técnicos ${ }^{44}$.

En la norma constitucional esta positivación se produce a partir de dos preceptos. En primer lugar, el artículo 20.1.b) reconoce y protege el derecho "a la producción y creación literaria, artística, científica y técnica", de donde se deduce la citada libertad de investigación científica, noción que, como se indicó, refiere bien esa composición mixta entre producción y creación, entre técnica e imaginación de la actividad científica. Aunque se profundizará después en este contenido ${ }^{45}$, sirva destacar aquí que

Está protegido por el derecho fundamental todo el proceso que abarca desde la decisión sobre el objeto de la investigación hasta la comunicación de la aportación al conocimiento alcanzada, pasando por la fase medular intermedia del trabajo intelectual de obtención de nuevo saber a partir del material que se utiliza como presupuesto de la investigación, conforme al plan y a la metodología que deban aplicarse ${ }^{46}$.

En segundo lugar, el artículo 44.2 CE, cuya ubicación sistemática es bien distinta, establece que "los poderes públicos promoverán la ciencia y la investigación científica y técnica en beneficio del interés general".

En cuanto a la positivación de este derecho en las normas internacionales, conviene destacar su presencia en la Declaración Universal de Derechos Humanos, de 10 de diciembre de $1948^{47}$, tanto en lo incluido por el reconocimiento de la libertad de expresión ${ }^{48}$, como por el derecho de participación en

44 Véase, en apoyo de esta perspectiva, ARRUEGO “El derecho fundamental a la investigación científica en la Constitución Española de 1978”, cit., pp. 37-40, que también señala las reticencias de Chueca hacia las constituciones que, como la alemana o la suiza, al contener previsiones constitucionales "fuertes" en esta materia, pierden pronto conexión con el presente.

45 Vid. infra secc. 3.1. También puede encontrarse un resumen de la constitucionalización concreta de este derecho en los Estados del entorno europeo en A. ELVIRA, "El derecho a la investigación científica en el marco de la Unión Europea” en R. L. CHUECA (ed.), La investigación científica como derecho fundamental, cit., pp. 69-100.

46 J. M. RODRÍGUEZ DE SANTIAGO, "Libertad de investigación científica y sexenios", Revista catalana de Dret Públic, núm. 44, 2012, p. 229.

47 Véase AHUMADA, “La libertad de investigación científica: Panorama de su situación en el constitucionalismo comparado y en el Derecho Internacional, cit., p. 428 para un análisis de la misma a este respecto.

48 El artículo 19 de esta Declaración establece que "todo individuo tiene derecho a la libertad de opinión y de expresión; este derecho incluye el no ser molestado a causa de sus 
el progreso científico, en los beneficios que produzca y en el disfrute de los intereses morales y materiales que le correspondan ${ }^{49}$. Tales principios también encuentran reconocimiento en el PIDCP, donde la "libertad de buscar, recibir y difundir informaciones de toda índole" debe entenderse abarcativa de la actividad de investigación ${ }^{50}$, así como, con toda claridad, en el PIDESC, cuando su artículo 15:

después de consagrar el derecho a participar en la vida cultural (15.1.a), se refiere al derecho de toda persona a "gozar de los beneficios del progreso científico y de sus aplicaciones" (15.1.b) y a "beneficiarse de la protección de los intereses morales y materiales que le correspondan por razón de las producciones científicas, literarias y artísticas de que sea autora" (15.1.c). La misma disposición establece, entre las medidas que los Estados Partes deberán adoptar para asegurar el pleno ejercicio de este derecho, "las necesarias para la conservación, el desarrollo y la difusión de la ciencia y de la cultura" (15.2), comprometiéndose a "respetar la indispensable libertad para la investigación científica y para la actividad creadora" (15.3) y a reconocer "los beneficios que derivan del fomento y desarrollo de la cooperación y de las relaciones internacionales en cuestiones científicas y culturales" (15.4) $)^{51}$

opiniones, el de investigar y recibir informaciones y opiniones, y el de difundirlas, sin limitación de fronteras, por cualquier medio de expresión."

49 El artículo 27 de la misma Declaración establece, en su apartado primero, que "toda persona tiene derecho a tomar parte libremente en la vida cultural de la comunidad, a gozar de las artes y a participar en el progreso científico y en los beneficios que de él resulten" y, en su apartado segundo, que "toda persona tiene derecho a la protección de los intereses morales y materiales que le correspondan por razón de las producciones científicas, literarias o artísticas de que sea autora".

50 En este sentido, también ARRUEGO, "El derecho fundamental a la investigación científica en la Constitución Española de 1978", cit. p. 40, con apoyo en la libertad de pensamiento reconocida en el art. 18 y en el citado 19.2, que establece que "toda persona tiene derecho a la libertad de expresión; este derecho comprende la libertad de buscar, recibir y difundir informaciones e ideas de toda índole". AHUMADA, "La libertad de investigación científica: Panorama de su situación en el constitucionalismo comparado y en el Derecho Internacional", cit., p. 429 entiende que el establecimiento de límites en el PIDCP a los experimentos médicos y científicos también puede entenderse como una positivación concreta de la libertad científica con respeto a valores fundamentales como la dignidad o la integridad física y moral. En concreto, el artículo 7 in fine establece, en vínculo con la prohibición de la tortura, que "en particular, nadie será sometido sin su libre consentimiento a experimentos médicos o científicos".

51 AHUMADA, “La libertad de investigación científica: Panorama de su situación en el constitucionalismo comparado y en el Derecho Internacional", cit. pp. 429-430. Para una consideración actualizada de la efectividad de estos derechos, resulta muy útil el contenido de F. SHAHEED, Report on the Copyright Policy \& the right to science \& culture. Special rapporteur in the field of cultural rights (A/HRC/28/57), Geneva, UNGA, Human Rights Council, 
En el plano europeo conviene considerar el reconocimiento que hace la Carta de Derechos Fundamentales de la Unión, en su artículo 13, de la libertad de investigación científica, de manera autónoma respecto a la libertad de expresión ${ }^{52}$, en una positivación coherente con los valores y objetivos de la Unión Europea $^{53}$.

Debido a la heterogeneidad y amplitud de esta recopilación normativa, se suscitan algunas cuestiones preliminares sobre el funcionamiento de este derecho a la ciencia. En primer lugar, la de quién puede ser titular de este derecho. Por una parte, parece claro que no se establecen discriminaciones entre su ejercicio dentro de instituciones públicas o privadas y que se extiende a la actividad de los profesionales universitarios, en cuyas figuras confluyen las actividades de docencia e investigación ${ }^{54}$ y resulta pertinente la libertad de cátedra (artículo 20.1.c CE). Por otra parte, también es admisible pensar que no solo las personas físicas, sino también las personas jurídicas, pueden ser titulares de este derecho, no tanto en lo concerniente a la actividad creativa última que siempre es individualizable en un número de sujetos determinados, por extenso que este sea, y de donde se sigue la inalienabilidad de los derechos de autor en su vertiente moral; sino en lo relativo a la definición y ejecución autónomas de una agenda de investigación, como podría ser la de una universidad ${ }^{55}$, donde es clara la correspondencia con los valores constitucionales.

2014 y F. SHAHEED, The right to benefit from scientific progress and its applications. Special rapporteur in the field of cultural rights (A/HRC/20/26), Geneva, UNGA, Human Rights Council, 2012, así como las recomendaciones y declaraciones de la UNESCO y el Consejo Internacional para la Ciencia (ICSU).

52 Véase AHUMADA, “La libertad de investigación científica: Panorama de su situación en el constitucionalismo comparado y en el Derecho Internacional", cit. p. 431 y, aunque sobre un conjunto de cuestiones distintas a las que pretende abordar este artículo, también el llamado Convenio de Oviedo, de 1999, respecto a la relación entre dignidad humana y las aplicaciones de la biología y medicina.

53 Véanse los fines relativos a "la elevación del nivel y de la calidad de vida" (artículo 2) y el medio de "el fomento de la investigación y del desarrollo tecnológico" (articulo 3.m) del Tratado Constitutivo.

54 Véase por ejemplo el enfoque de la Ley Orgánica 6/2001, de 21 de diciembre, de Universidades (en adelante, LOU) cuando establece, en sus artículos 40.1 y 40.1 bis, que "la investigación es un derecho y un deber del personal docente e investigador de las Universidades" y que "la universidad apoyará y promoverá la dedicación a la investigación de la totalidad del Personal Docente e Investigador permanente".

55 M. CUETO PÉREZ, “El régimen jurídico de la investigación en la universidad: novedades de la LOU”, Revista de Administración Pública, núm. 161, 2003, p. 486 vincula el desplie-

ISSN: 1133-0937

DOI: https://doi.org/10.20318/dyl.2021.6110
DERECHOS Y LIBERTADES

Número 45, Época II, junio 2021, pp. 327-364 
Al margen de este último supuesto, la efectividad del derecho va a requerir su adaptación a las formas contemporáneas de investigación científica, que son principalmente de carácter colectivo y colaborativo, como corresponde al funcionamiento de los bienes comunes ${ }^{56}$. De hecho, las reflexiones sobre su gobernanza ya han avanzado en las últimas décadas la discusión acerca del ejercicio de un derecho por parte de una colectividad, sin que ello vaya en detrimento de la libertad específica, en este caso de investigación, de ninguna de las personas físicas que la integran ${ }^{57}$.

También resulta decisiva para la efectividad de este derecho la implicación del sector privado. Si se atiende a las dinámicas de desarrollo y efectuación de la libertad de investigación científica, puede observarse que no tiene sentido limitar las obligaciones derivadas de la misma a los Estados, ya que, en primer lugar, buena parte de la investigación se realiza en el sector privado y, en segundo lugar, incluso cuando esta se impulsa o se financia mayoritariamente desde el sector público, la actividad científica contemporánea ha alcanzado tal nivel de complejidad y coste, que su fomento es inviable sin la contribución del sector privado. Por el momento, este cambio de perspectiva apenas se ha recogido solo en instrumentos de soft law, como los "Principios rectores sobre empresas y los derechos humanos" que publicó Naciones Unidas en 2011, pero, al menos en un plano conceptual y hermenéutico, carece de sentido limitar las obligaciones derivadas de este derecho a los Estados ${ }^{58}$.

Introducidas de manera sucinta estas cuestiones previas, es momento de considerar el núcleo de la positivación de este derecho a la ciencia, cual es la relación de aspectos muy distintos, desde el punto de vista conceptual pero también del relativo a las obligaciones exigibles a los Estados y a terceros para su efectividad. Todo ello se ha establecido además mediante instrumentos de positivación heterogéneos, que adolecen de ciertas ausencias, sobre

gue de la libertad de investigación científica en el plano colectivo de la institución universitaria al reconocimiento de la autonomía universitaria en el artículo 27.10 CE.

56 Vid. supra secc. 1.2. La propia LOU asume también este enfoque cuando remite, en su artículo 40.2, a los grupos de investigación como la unidad básica de los procesos de investigación.

57 Véase ÖSTROM “Governing the commons: The evolution of institutions for collective action", cit. y ÖSTROM y HESS, Los bienes comunes del conocimiento, cit.

58 Véase E. VAYENA y J. TASIOULAS, "The dynamics of big data and human rights: The case of scientific research", Philosophical Transactions of the Royal Society B, núm. 374 vol. 2083, 2016, pp. 8-9 (https://doi.org/10.1098/rsta.2016.0129). 
todo en cuanto a mecanismos legislativos y políticos para garantizar su efectividad $^{59}$. Con el fin de abordar esta tarea, se van a distinguir tres dimensiones del derecho a la ciencia. En primer lugar, la libertad de investigación científica, en cuanto al derecho a no soportar injerencias a la libertad en el proceso de investigación, consagrado en el artículo 20.1.b) CE. En segundo lugar, el derecho al acceso a la ciencia, a su realización y al disfrute de sus beneficios que, a falta de una positivación más explícita en la norma constitucional española, encuentra base en los artículos 15 del PIDESC y 19.2 del PIDCP. Y, en tercer lugar, el derecho a que el Estado realice una labor de fomento de la ciencia y la investigación científica y técnica en beneficio del interés general, consagrado en el artículo 44.2 CE.

La utilidad de esta distinción no debe empañar la realidad de que se trata de dimensiones de un mismo derecho ${ }^{60}$, como se demuestra si forzamos los argumentos que se basan en la autonomía de estas dimensiones o, lo que es más habitual, la reducción de este derecho a no sufrir injerencias externas en el desarrollo de la actividad científica. Es evidente que no cabe afirmar la existencia de una libertad científica al margen de la existencia de toda una actividad de producción de esa libertad por parte del Estado, en términos de provisión de educación científica básica y superior, de infraestructuras, personal investigador, títulos y acreditaciones y demás instrumentos burocráticos para la configuración de una suerte de servicio público de producción y apoyo a la investigación científica. Del mismo modo, aunque dentro del derecho a acceder a la ciencia, pueda aislarse la situación de quien no pretende tener más relación con la ciencia que disfrutar de sus beneficios, a modo de simple persona usuaria, la idea de acceder a la investigación exige la posibilidad de participar, de que cualquier persona con capacidades para ello pueda realizar cierta actividad científica. Se trata de un aspecto inescindible por completo de la libertad de investigación científica, ya que no cabría afirmar que, por ejemplo, una sociedad que no establece ningún medio para que cualquier persona practique una cierta actividad científica, como podría ser una sociedad que solo permite educarse en la ciencia a determinadas castas superiores, respeta el derecho a la ciencia, por mucho que esas personas que sí tienen acceso no sufran mayores injerencias en su actividad.

\footnotetext{
59 Este asunto exige la ampliación de la presente investigación.

60 Véase CALVO, "Derechos sociales : algunas propuestas para seguir avanzando en tiempos de incertidumbre", p. 147. 


\subsection{Libertad de investigación científica}

El reconocimiento de la libertad de investigación científica en el artículo 20.1.b) CE implica "un derecho fundamental subjetivo a favor del investigador para evitar intromisiones o interferencias en el desarrollo de su actividad" ${ }^{\prime 1}$. Esta es la dimensión del derecho de la que se ha ocupado principalmente el $\mathrm{TC}^{62}$, advirtiéndose en cambio menor consideración de su dimensión objetiva ${ }^{63}$, esto es, de las obligaciones de los poderes públicos y de terceros para hacer efectiva tal libertad ${ }^{64}$.

La configuración tradicional de este derecho lo ha aproximado a los derechos de libertad de pensamiento y expresión pero existe consenso en que, a pesar de las evidentes continuidades ${ }^{65}$, su constitucionalización en el interior del núcleo duro de los derechos fundamentales amerita una consideración autónoma. Ello se encuentra, de hecho, en la línea del constitucionalismo de posguerra y su coherencia con la complejización de los procesos productivos y científicos ${ }^{66}$.

En esa misma STC 51/2008, se señala que "el objetivo principal (...) es proteger la libertad del proceso creativo". Desde la perspectiva del presente trabajo, poner el foco de la protección en el proceso creativo es relevante

61 Véase J. CABRERA RODRÍGUEZ, “El derecho fundamental a la libertad de investigación científica (art. 20.1. CE) como principio organizativo. El caso de las reales academias", Revista de Administración Pública, núm. 19(enero-abril), 2014, p. 127.

62 Véanse las SSTC 153/1985, FJ 5; 26/1987, FJ 4; 90/1992, 43/2004 y 51/2008, entre otras pertinentes.

63 Véase CABRERA, “El derecho fundamental a la libertad de investigación científica (art. 20.1. CE) como principio organizativo. El caso de las reales academias”, cit. p. 131.

64 Vid. infra seccs. 3.2 y 3.3.

65 Por ejemplo que, cuando se pretende identificar este derecho en el PIDCP, se hace deduciéndolo de las referencias a esas libertades clásicas en los artículos 18 y 19.2, como se ha mostrado al inicio de esta sección.

66 D. FERNÁNDEZ DE GATTA SÁNCHEZ, “La libertad de creación científica en la evolución de la ciencia y la tecnología" en F. LÓPEZ RAMÓN et al. (eds.), Organización de la Universidad y la Ciencia, cit. pp. 110 y ss señala que, si bien la jurisprudencia constitucional considera en sus inicios que el contenido del art. 20.1.b) "no es sino una concreción del derecho (...) a expresar y difundir libremente pensamientos, ideas y opiniones" (STC 153/1985), ésta evoluciona hasta referirse a la libertad de creación científica y artística como a "un derecho fundamental específico" (STC 51/2008, con las salvedades que aconseja el hecho de que su objeto no es una pieza de producción científica, sino literaria). Véase ARRUEGO, "El derecho fundamental a la investigación científica en la Constitución Española de 1978”, cit. p. 46 para ampliar el análisis sobre la relevancia de esta sentencia en el proceso de autonomización de este derecho. 
porque subraya que el proceso de investigación no es una acción puntual, como por ejemplo lo sería divulgar los resultados de una investigación dada, sobre la que no debe intervenirse de manera restrictiva, sino que se trata de un proceso. Resulta claro que la ausencia de tales injerencias forma parte del contenido esencial del derecho pero esta configuración procesual, en primer lugar, invita a pensar la garantía de este derecho como el establecimiento de un dispositivo que lo haga sostenible y no solo que evite aquellas injerencias puntuales. De este modo, la dimensión positiva del derecho se encuentra en el primer plano también de la libertad del artículo 20.1.b CE, disolviendo así la dicotomía con la que se ha comprendido este derecho tradicionalmente. Tal dicotomía propone que el artículo 20 se refiere al derecho liberal negativo, que cuenta con plenas garantías, mientras el resto de dimensiones del derecho a la ciencia conforman un derecho social positivo, que se encuentra positivizado en otros lugares y cuyas obligaciones derivadas están pendientes del desarrollo legislativo y de la evolución de las cuentas del Estado. En segundo lugar, dicha configuración procesual de la libertad científica permite, desde el enfoque de sus vulneraciones ${ }^{67}$, identificar con más eficacia los distintos puntos críticos dentro del proceso de científico y diseñar mecanismos de garantía adecuados. A pesar de lo razonable de esta interpretación, conviene reconocer que el enfoque dominante sigue siendo el que podría resumirse como:

La libre investigación científica es, primariamente, un derecho fundamental de libertad (frente al Estado), no de prestación [como el derecho a la educación (art. 27 CE), por ejemplo], que, sin embargo, se ejerce, en gran medida, dentro del Estado (en las universidades y organismos públicos de investigación), en y a través de organizaciones estatales. Al menos en ese sentido, puede hablarse de una institucionalización estatal de la ciencia ${ }^{68}$.

A partir de esta base, conviene realizar dos matizaciones. En primer lugar, desde una perspectiva pragmática y conforme al citado enfoque de la vulneración de los derechos, es necesario resaltar la existencia de nuevos riesgos, que se suman a la tradicional injerencia estatal o de terceros sobre la libertad científica. La estrategia implementada por los Estados sociales para

67 Véase A. R. CHAPMAN, “Violations Approach”, Human Rights Quarterly, núm. 18 vol. 1, 1996, pp. 23-66 para profundizar sobre este enfoque pragmático que considera el estudio de la efectividad de los derechos a partir de sus vulneraciones concretas y no tanto del punto de partida que supone su contenido normativo.

68 RODRÍGUEZ, “Libertad de investigación científica y sexenios”, cit. p. 231.

ISSN: 1133-0937

DOI: https://doi.org/10.20318/dyl.2021.6110
DERECHOS Y LIBERTADES

Número 45, Época II, junio 2021, pp. 327-364 
la gestión de la crisis de 2008, basada en la austeridad ${ }^{69}$ o limitación de la inversión pública en las áreas claves del Estado Social y los sectores productivos, ha reducido la intervención promocional del Estado en esta y otras materias. En contraste con una primera intuición, la austeridad no solo afectaría a los derechos sociale ${ }^{70}$, sino también a las libertades, al deteriorar la calidad del proceso científico creativo y hacerlo eventualmente insostenible o imposible de desarrollar, al menos en instituciones españolas. Tal ocurre, por ejemplo, a consecuencia de la reducción de la inversión en educación superior e $\mathrm{I}+\mathrm{D}+\mathrm{i}^{71}$, lo que afecta al desarrollo de nuevas vocaciones y carreras científicas, a la cantidad de empleos dedicados a este sector en España ${ }^{72}$, o a las dificultades para percibir y ejecutar los fondos de investigación.

En segundo lugar, al examinar la propia genealogía de estas libertades, se pueden avanzar nuevas conclusiones sobre sus contenidos. Por una parte, estas libertades adoptan la premisa de que existe una esfera de autonomía personal anidada a la dignidad de la persona que es obligatorio proteger frente a las injerencias externas, sean de un poder político organizado o sean de terceros. Qué libertades concretas forman parte de esa esfera es una cuestión axiológica y política dinámica pero, en general, resulta aceptado incluir libertades más naturalizadas, como la libertad ambulatoria, que otras cuyos objetos son productos sociales más complejos e institucionalizados, como ocurre con la propiedad o la propia actividad científica. Con respecto a estos objetos sociales complejos, resulta evidente que la efectividad de su protección no exige solo una evitación de injerencias en su uso y disfrute. Al contrario, circunstancias como un grado elevado de seguridad jurídica en cuanto a las normas aplicables, al funcionamiento de dicho objeto y a los mecanismos de tutela se vuelven indispensables. Cuando se trata de garantizar estos segundos aspectos, tal labor ya no se realiza por lo general frente

69 Véanse, entre muchas referencias, D. BAKER, “The Myth of Expansionary Fiscal Austerity", CEPR Reports and Issue Briefs, núm. 23, 2010, pp. 14 (https://ideas.repec.org/p/epo/ papers/2010-23.html) y J. E. STIGLITZ, People, Power, and Profits: Progressive Capitalism for an Age of Discontent, Penguin, London, 2019.

70 A pesar de que este no es el lugar oportuno para su discusión, convendría profundizar sobre los motivos por los que esto resulta en general aceptable en el contexto de un Estado Social y Democrático de Derecho.

71 En M. BLASCO et al., ¡Queremos inventar nosotros, por favor!, 29 de marzo de 2019 (https://elpais.com/elpais/2019/03/28/ciencia/1553794522_288589.html) un nutrido grupo de investigadores e investigadoras de prestigio resumían las reivindicaciones más acuciantes de la ciencia en España.

72 Véase nota 42 acerca del descenso en el número de investigadores e investigadoras.

DERECHOS Y LIBERTADES

ISSN: 1133-0937

Número 45, Época II, junio 2021, pp. 327-364

DOI: https://doi.org/10.20318/dyl.2021.6110 
al Estado o al poder político institucionalizado, sino precisamente a través de los mismos. Si se sigue el ejemplo de un objeto tan complejo y formalizado como la ciencia ${ }^{73}$, el razonamiento adquiere más fuerza porque, para la generación de esa libertad de investigación, es imprescindible el despliegue y mantenimiento de un marco de normatividad científica. Si se analiza el contenido de la libertad de investigación a la luz de esta circunstancia, se observa que la efectividad del citado derecho exige el cumplimiento acumulado de dos condiciones: 1) la ausencia de injerencias durante todo el proceso de investigación y 2) la creación y sostenimiento de un marco institucional y normativo en el que pudieran definirse, validarse y hacerse valer las formas científicas.

Además, lo particular del ámbito científico es que este no puede agotarse en un marco normativo e institucional de génesis estatal, sino que su normatividad implica al conjunto de la comunidad científica porque la ciencia es una actividad creativa pero no solo individual. Se trata de una actividad que adquiere tal condición en el marco de validación de una comunidad científica que, en cada caso, falsea las hipótesis, diseña y repite los experimentos o certifica la calidad del trabajo de los pares. Esa intervención distribuida termina por configurar el marco de normatividad en el que se efectúa el derecho y añade, por lo tanto, una tercera condición para considerar que es efectivo: la creación y sostenimiento de una comunidad científica que nutra y someta a juicio constante la creación y funcionamiento del marco institucional y normativo al que se aludió en la segunda condición.

En términos generales, esta comprensión de las libertades es coherente con la caracterización del proceso moderno de gubermentalización de las relaciones de poder como un proceso de estatización del poder ${ }^{74}$, a condición de que esto no se entienda como un poder totalitario, sino como una actividad más amplia, multidireccional y heterogénea, que en ocasiones se articula funcionalmente con las comunidades científicas y en ocasiones entra en conflicto con ellas por la autonomía y la dirección de los procesos científicos, como se verá a continuación. Respecto a esta situación, el giro hacia una gobernabilidad basada en la austeridad impone el reto de considerar un pensamiento de gobierno en el que se asuma el abandono del ethos expansivo por

\footnotetext{
73 Vid. supra secc. 1.1.

74 Entre distintas referencias, véase sobre todo M. FOUCAULT, Seguridad, territorio, población. Curso del Collège de France (1977-1978), Akal, Madrid, 2008 y D. VILA-VIÑAS, La gobernabilidad más allá de Foucault. Un marco para la teoría social y política contemporáneas, cit., pp. 49-50.
} 
parte del Estado para adoptar en cambio uno reflexivo, que le lleva a posponer su acción positiva sobre derechos configurados al calor de la gobernabilidad precedente, como el derecho a la ciencia.

Es precisamente en el tradicional conflicto entre el Estado y quien investiga o el conjunto de la comunidad científica, si se hace honor al funcionamiento actual de la ciencia, donde se observan algunas consecuencias de esta evolución. Las vulneraciones habituales a la libertad científica han tenido la forma bien de censura bien de subordinación de los procesos de investigación a intereses exteriores. Como garantía frente a estas vulneraciones no solo se ha positivizado dicha libertad, sino que también se ha avanzado en una progresiva autonomización de la ciencia respecto al poder político y en un fortalecimiento de la comunidad científica. Este último movimiento ha resultado muy eficaz, aunque haya tenido el "coste" de vincular la protección de este derecho a la asunción de las reglas del método científico, delimitado por esa comunidad ${ }^{75}$. Dicha autonomía adquiere distintas formas, desde la conocida autonomía universitaria y su impronta en los contenidos de educación superior y de las agendas de investigación ${ }^{76}$, hasta la validación de los avances científicos a través de los métodos de evaluación por pares o la relevancia de las agencias de acreditación, evaluación y asignación de fondos, compuestas por miembros de la comunidad científica. Como se indicó en la sección 2.1, esta reordenación del campo de vulneraciones del derecho a la ciencia no ha hecho desaparecer las tradicionales pero las posiciones críticas respecto a la configuración de este derecho ponen el foco en las causadas por la imposicion de una determinada concepción de la ciencia. Dada esta concepción predominantemente formal de la libertad de investigación científica, las vulneraciones se producirían hoy a través de mecanismos de estructuración, subjetivación e intervención encuadrados en las tecnologías de gobierno a distancia ${ }^{77}$, tales como criterios de medi-

\footnotetext{
75 Véase RODRÍGUEZ, “Libertad de investigación científica y sexenios”, cit. p. 233.

76 Nótese que este contenido también se encuentra positivizado en el núcleo de los derechos fundamentales (art. 27.10 CE) y que M. J. AGUDO ZAMORA, "El contenido del derecho a la autonomía universitaria en la Ley Orgánica de Universidades, Revista Vasca de Administración Pública, núm. 70, 2004, pp. 14 y ss. lo vincula con la libertad de cátedra (art. 20.1.c CE), formando ambas parte de lo que denomina "libertad académica" (pp. 3 y ss). CHAPMAN, "Towards an Understanding of the Right to Enjoy the Benefits of Scientifc Progress and its Application", cit., pp. 16 y 17 insiste también en este vínculo con la libertad académica desde una perspectiva internacional.

77 Véase, entre otras referencias, N. ROSE y P. MILLER, “Political power beyond the State: problematics of government", The British Journal of Sociology, núm. 43 vol. 2, 1992, pp. 172-205.
} 
ción, procedimientos de auditoría, burocratización de las tareas cotidianas ${ }^{78}$. Sin embargo y como ya se indicó al discutir la formalización de la ciencia, la cuestión no es tanto cuestionar la oportunidad de la medición (resulta difícil imaginar un conocimiento científico al margen de ciertos aparatos de estandarización), sino los objetivos en que se inscriben esas formas de racionalización de la actividad científica ${ }^{79}$.

\subsection{Derecho de acceso y participación en la ciencia}

La segunda dimensión del derecho a la ciencia que se pretende destacar es la relativa a participar en la actividad científica, tanto en los beneficios proporcionados por sus resultados como en todo el proceso de creación que constituye el núcleo de protección de este derecho fundamental. Ello es coherente con el vínculo entre este derecho y la dignidad humana, ya que los efectos emancipatorios de eventuales avances en el conocimiento solo se compadecen con la dignidad si son accesibles de manera universal, sin constituir el punto de partida de nuevas discriminaciones. En los términos de Naciones Unidas:

El contenido normativo del derecho a beneficiarse del progreso científico y sus aplicaciones incluye: a) el acceso de todos, sin discriminación, a los beneficios de la ciencia; b) oportunidades para todos de contribuir a la actividad científica y la libertad indispensable para la investigación científica; c) la participación de individuos y comunidades en la adopción de decisiones ${ }^{80}$,

78 Numerosos trabajos han criticado diferentes aspectos de este sistema de control-validación de la investigación científica. Véase AMIGOT cit. sobre las técnicas de control social del profesorado a partir de un análisis foucaultiano de su evaluación. También, RODRÍGUEZ, "Libertad de investigación científica y sexenios", cit. sobre los efectos del sistema de reconocimiento de sexenios al personal docente e investigador, así como C.A. CHAPMAN et al., "Games academics play and their consequences: How authorship, h-index and journal impact factors are shaping the future of academia", Proceedings of the Royal Society B: Biological Sciences, núm. 286 vol. 1916, 2019 (https://doi.org/10.1098/rspb.2019.2047) sobre los perjuicios para la calidad científica del sistema de citas y publicaciones. Así como FERREIRO, "Mercantilizacón y precarización del conocimiento: El proceso de Bolonia", cit., sobre la manera en que la conocida como Reforma de Bolonia de la univeresidad concretaba esa racionalidad para la educación superior.

79 Vid. supra secc. 2.2, en cuanto a la superposición de los objetivos de mercado sobre los inmanentes a la ciencia.

80 SHAHEED, The right to benefit from scientific progress and its applications. Special rapporteur in the field of cultural rights (A/HRC/20/26), cit. Par. 25, p. 9. Nótese que

ISSN: 1133-0937

DOI: https://doi.org/10.20318/dyl.2021.6110
DERECHOS Y LIBERTADES

Número 45, Época II, junio 2021, pp. 327-364 
Estos contenidos se han trasladado a las normas positivas de mayor rango. En el ámbito internacional, resulta particularmente explícito el reconocimiento del artículo 15 del PIDESC ${ }^{81}$. En la CE, debe considerarse la obligación impuesta a los poderes públicos por el artículo 9.2 de "participación de todos los ciudadanos en la vida política, económica, cultural y social", lo que abarca sin duda a la vida científica. Al mismo tiempo, esta dimensión tiene evidentes conexiones con la libertad de investigación científica, reconocida en el artículo 20.1.b CE. Por una parte, se convino en que la titularidad de esta libertad no era solo individual, sino colectiva y debía incluirse en su ejercicio y disfrute al conjunto de la ciudadanía. Por otra, se apuntó el rol de la comunidad científica en la definición de lo científico como objeto de tutela y en la encarnación del marco institucional en que se haría viable. A este respecto, si bien es razonable que la participación y gobernanza de esa comunidad científica se rija por criterios científicos, y que ello module la participación, no lo es que aquélla se diseñe como una comunidad cerrada, de la que no pueda formar parte, siquiera eventualmente, cualquier persona que operare conforme a esos criterios, lo que supondría una suerte de revitalización de principios de dudoso valor científico, como el de autoridad, en esta ocasión de una comunidad dada. Tampoco es compatible con una ciencia ligada a la dignidad humana abandonar la ambición de que mayores proporciones de la ciudadanía formen parte de sus procesos, si no de manera profesional, sí en una definición heterogénea de sus objetivos y métodos y en un disfrute universal de sus beneficios.

Como resulta lógico, este derecho se ha desarrollado sobre todo en ámbitos en los que el avance científico ha exigido la concreción de estas demandas y ha suscitado conflictos en cuanto al acceso de individuos y comunidades, como ha ocurrido en el ámbito de la investigación biomédica ${ }^{82}$ y de la inves-

Shaheed incluye también el “d) un entorno favorable a la conservación, desarrollo y difusión de la ciencia y la tecnología", aunque este contenido se encuadra mejor conceptualmente en la dimensión del derecho a la ciencia que se analizará en el siguiente apartado.

81 Vid. supra secc. 3. Puede profundizarse en las normas internacionales que han positivizado este derecho en S. P. MARKS, "Human Rights and the Challenges of Science and Technology", Science and Engineering Ethics, núm 12 (February), 2014, pp. 2 y ss.

82 Véase MARKS “Human Rights and the Challenges of Science and Technology", cit. y M. A. AHUMADA CANABES, "El derecho a gozar de los beneficios de la ciencia: Una aproximación a su contenido, considerando las Declaraciones de la UNESCO sobre el genoma, datos genéticos humanos y bioética", Revista de derecho y genoma humano: genética, biotecnología y medicina avanzada, núm 42, 2015, pp. 27-68, para profundizar sobre los desarrollos en este ámbito. 
tigación sobre biodiversidad. En este último ámbito, el derecho de acceso a la ciencia revela un vínculo esencial entre los planos económico y democrático. En primer lugar, cuando los conocimientos comunitarios muestran ser indispensables para el avance del conocimiento científico y adquieren también un valor en el mercado, surge el reto de cómo esta circunstancia puede ser un factor de desarrollo de las propias comunidades y no un supuesto de simple extracción de su patrimonio a favor de ciertas instituciones científicas y comerciales. Cobra sentido aquí el aspecto económico del derecho a disfrutar de los beneficios de la ciencia, "como una herramienta para la inclusión a través de las culturas y el empoderamiento de los distintos actores" ${ }^{83}$.

En segundo lugar, pronto se hace evidente que la participación en los beneficios no es suficiente si no se sigue de la posibilidad de que las mismas comunidades participen durante todo el proceso científico y no solo en la puesta a disposición inicial de sus saberes o en la recepción final de una proporción de los réditos obtenidos. Participar es, en cambio, formar parte de las decisiones estratégicas sobre la definición de las agendas de investigación, los métodos de obtención y reproducción de la información biológica o las formas de transferencia de esos conocimientos, incluidas las relativas a su comercialización y a las eventuales condiciones de la misma ${ }^{84}$. Todo ello constituye un elemento diferencial del derecho a la ciencia respecto a otros derechos sociales ${ }^{85}$.

La relevancia de la participación también introduce requerimientos específicos en cuanto a las garantías. Si se tratara solo de redistribuir los beneficios de la investigación, tanto comunidades como Estados podrían desempeñar un rol escasamente activo en el reparto y recepción de los beneficios. Sin embargo, hacer efectiva la participación exige de los segundos una inter-

83 Véase E. MORGERA, "Fair and Equitable Benefit-Sharing at the Cross-Roads of the Human Right to Science and International Biodiversity Law", Laws, núm. 4, 2015, p. 826 (https://doi.org/10.3390/laws4040803) y S. GOLINELLI et al., "Biodiversidad: ciencia ciudadana, saberes ancestrales y biodiversidad aplicada en la economía social del conocimiento", en D. VILA-VIÑAS (eds.) Buen Conocer - FLOK Society. Modelos sostenibles y politicas públicas para una economía social del conocimiento común y abierto en el Ecuador, cit., pp. 401-456 (http://book. floksociety.org/ec/2/2-2-biodiversidad-ciencia-ciudadana-saberes-ancestrales-y-biodiversidad-aplicadaen-la-economia-social-del-conocimiento) respecto a la tensión entre una regulación más proclive a la investigación y otra a la protección de las comunidades.

84 Véase MORGERA, "Fair and Equitable Benefit-Sharing at the Cross-Roads of the Human Right to Science and International Biodiversity Law", cit. pp. 813 y ss.

85 Véase VAYENA, "The dynamics of big data and human rights: The case of scientific research", cit. p. 5 . 
vención mayor, que la anime y que consiga que sectores crecientes de la población pasen de la posición de personas beneficiarias de los avances científicos a personas partícipes de esos avances ${ }^{86}$. Para ello, tampoco es suficiente la acción unilateral del Estado, por proactiva que fuera, sino que esta debe coordinarse con las propias comunidades beneficiarias - agentes. Aunque la complejidad técnica de establecer dispositivos que garanticen este derecho se escapa a las posibilidades del presente artículo, sirva resaltar que las estrategias de gobernanza de los comunes, basadas en el principio democrático de que toda la comunidad que contribuye a su formación, que los disfruta y que es responsable de su viabilidad, es también responsable de su gobernanza, resulta pertinente para el ámbito científico, toda vez que el conocimiento puede categorizarse como un bien común del que no cabe ser un simple destinatario pasivo de los beneficios, sino un digno partícipe en su destino ${ }^{87}$.

De conformidad con el marco analítico que parte de las vulneraciones de los derechos y que se ha propuesto, el derecho de acceso se enfrenta a algunas situaciones de inefectividad. La principal de ellas es la causada por el desequilibrio de poder en el acceso a la ciencia. En el contexto de una ciencia que cada vez requiere más recursos para su despliegue, se genera desigualdad entre la posición de los distintos actores. Quienes detentan los recursos económicos $\mathrm{y}$, con ello, adquieren una posición prevalente para marcar la agenda científica y capturar los beneficios de su avance ${ }^{88}$ prevalecen frente a la generalidad de los miembros de la comunidad científica. Estos últimos producen y protagonizan los avances del conocimiento pero encuentran enormes limitaciones en su acceso a las decisiones estratégicas y al disfrute

86 Como señala MORGERA, "Fair and Equitable Benefit-Sharing at the Cross-Roads of the Human Right to Science and International Biodiversity Law", cit. p. 813 respecto a la investigación en biodiversidad, esto exige de los Estados "construir/promover las capacidades de los beneficiarios para conducir por ellos mismos la investigación de base biológica".

87 Vid. supra secc. 2.2.

88 Véase MORGERA, "Fair and Equitable Benefit-Sharing at the Cross-Roads of the Human Right to Science and International Biodiversity Law", cit., pp. 805 y ss, que destaca como factores de estas vulneraciones el impacto de la agenda política neoliberal, en la forma de una disminución de los fondos públicos, el estrechamiento de las agendas científicas en favor de los agentes comerciales y la intensificación de los derechos de propiedad intelectual en detrimento de la divulgación de los hallazgos científicos. También S. HOREL, Lobbytomía, cit. ha mostrado cómo, en sectores como el farmacéutico o el agroalimentario, con un alto impacto económico, el peso de los intereses económicos llega incluso a alterar los parámetros científicos que deberían servir de base para las regulaciones. 
de los beneficios ${ }^{89}$, como se ha evidenciado a propósito de las brechas de género ${ }^{90}$. Por último, se situarían las comunidades y grupos sociales en riesgo de exclusión respecto a la actividad científica, que ven vulnerado con frecuencia este derecho, a pesar de que algunas de ellas detenten conocimientos básicos para su avance.

Ante esta situación, la obligación de los poderes públicos es establecer medidas para remover esas brechas de acceso y participación, con especial atención a los grupos vulnerables ${ }^{91}$. Sin embargo, desde la perspectiva de la garantía de estos derechos, se ha denunciado con reiteración la falta de actividad suficiente de los Estados para desarrollar el alcance, el contenido normativo y sus propias obligaciones a este respecto ${ }^{92}$. Existen para ello dos factores que operan como lastre y que se analizarán con más detenimiento en el apartado siguiente. En primer lugar, el discutido encasillamiento de estos contenidos como derechos económicos, sociales y culturales, con su correspondiente subalternización respecto a otros derechos y, en segundo lugar, la consolidación

89 Un ejemplo paradigmático de los problemas de acceso es el que suscita el ámbito de las publicaciones científicas de alto impacto. Realizadas con las contribuciones científicas generadas por proyectos de investigación y la revisión gratuita de pares, tienen a menudo precios altos que deben sufragar, normalmente de nuevo con fondos públicos, las bibliotecas académicas que puedan, siendo inviable el acceso para el resto. Por otro lado, DARNACULLETA, "Libertad de investigación científica y la promoción de la ciencia en beneficio del interés general", cit. p. 22 señala el problema del acceso a las investigaciones que, pese a contar con financiación pública, se rigen por acuerdos de confidencialidad que impiden el acceso a sus datos y resultados. Véase G. DOMÉNECH PASCUAL, “Que innoven ellos. Por qué la ciencia jurídica española es tan poco original, creativa e innovadora", InDret, núm. 2, 2016, pp. 2-41, al perjuicio que en ocasiones supone para la investigación en España en el ámbito jurídico la compatibilidad de las posiciones de investigación con la actividad profesional.

90 Por ejemplo, en una institución académica concreta, como la Universidad de Zaragoza, la proporción entre investigadores e investigadoras tiende a igualarse pero ello no se refleja aún en la capacidad de captación de fondos (en 2018 solo el 16,8\% de los fondos fueron captados por mujeres) y en la proporción de mujeres como investigadoras principales (36\% de los proyectos en 2018). Para más datos véase KAMPAL DATA SOLUTIONS, "Estudio de Género en la I+D+i en la Universidad de Zaragoza. Presentación”, Vicerrectorado de Transferencia e Innovación Tecnológica y el Vicerrectorado de Cultura y Proyección Social; Instituto Aragonés de la Mujer del Gobierno de Aragón, 2019, nov. (http://prensa.unizar.es/notasprensa/anexos/0_Estudio\%20genero\%20investiga\%20UZ.pdf).

91 CHAPMAN, ,'Towards an Understanding of the Right to Enjoy the Benefits of Scientifc Progress and its Application", cit. p. 14 defiende que este último es uno de los principios más relevantes en el desarrollo científico conforme a un enfoque de derechos humanos.

92 Véase SHAHEED, The right to benefit from scientific progress and its applications. Special rapporteur in the field of cultural rights (A/HRC/20/26), cit. Par. 30 a 43, sobre el cumplimiento de las obligaciones por parte de los Estados.

ISSN: 1133-0937

DOI: https://doi.org/10.20318/dyl.2021.6110
DERECHOS Y LIBERTADES

Número 45, Época II, junio 2021, pp. 327-364 
de una agenda de austeridad que, en relación con lo anterior, justifica la inacción de los Estados en favor de una reducción del gasto público.

\subsection{Promoción de la investigación científica}

La tercera dimensión del derecho a la ciencia se refiere a la posibilidad de exigir a los poderes públicos que realicen una labor de promoción de la ciencia y de la investigación científica y técnica en beneficio del interés general, tal como consagra el artículo $44.2 \mathrm{CE}$. Desde la perspectiva del reconocimiento de determinados valores y contenidos políticos, en este artículo confluyen dos elementos. Por un lado, esta positivación incide en que la ciencia y sus avances se consideran algo apreciable en sí mismos, dentro del contexto axiológico que se definió en la sección 2.2. Por otro lado, hace explícitas las obligaciones positivas de los poderes públicos en esta materia, con el objetivo de alcanzar la efectividad de los contenidos del derecho expuestos. Por ejemplo, la obligación asignada a los poderes públicos en el artículo 44.2 CE prolonga y concreta la obligación genérica establecida en el artículo 9.2 $\mathrm{CE}$, relativa a la remoción de los obstáculos para la participación en la vida científica y una mayor igualdad de oportunidades en este ámbito ${ }^{93}$.

La doctrina constitucional española tiende a considerar que se trata de un derecho de carácter subjetivo, del que se sigue la obligación de los poderes públicos de implementar una política pública prestacional, pero que carece de eficacia directa, exigiendo en cambio una configuración legal de cada una de estas obligaciones para hacerlas efectivas ${ }^{94}$, tal como sucede con el derecho a la promoción del acceso a la cultura o con otros principios rectores de la política económica y social, ubicados en el mismo capítulo III del Título I CE ${ }^{95}$.

93 Cuestión subrayada además por la presencia del fomento de la cultura y de la ciencia en el mismo artículo 44 CE, siquiera en apartados distintos. Véase R. VELÁZQUEZ ÁLVAREZ, "Artículo 44" en C. MONTESINOS et al. (eds.), Comentario a la Constitución Española: 40 aniversario 1978-2018: Libro-homenaje a Luis López Guerra, Tirant lo Blanch, Valencia, vol. 1, 2018, p. 844 y 847.

94 Véase en esta posición a VELÁZQUEZ, “Artículo 44”, cit., entre otras referencias que se irán desgranando.

95 En el ámbito internacional, AHUMADA cit. pp. 423 y ss, comparte este enfoque para las constituciones portuguesa (artículo 77) y brasileña (artículos 218 y 225), aunque las señala como ejemplos de regulación constitucional más precisa en las obligaciones impuestas al Estado y en el reconocimiento del impacto de la ciencia en la producción. 
Existe asimismo cierta controversia sobre el carácter autónomo de esta dimensión promocional del derecho a la ciencia respecto al derecho a la cultura, no solo debido a las concomitancias conceptuales, sino a que tanto la CE, en su artículo 44, como el PIDESC, en su artículo 15, los establecen de manera conjunta. En este caso, buena parte de la doctrina española entiende que cabe distinguirlos ${ }^{96}$. Desde la perspectiva de los valores y contenidos políticos que vehiculan estos derechos, tiene sentido su ubicación conjunta, habitualmente posterior también al derecho a la educación, como aspectos relacionados entre sí y con el acceso al conocimiento como parte del proceso de libre determinación de la personalidad y acceso a una vida digna ${ }^{97}$. Ya en el interior del artículo 44.2 CE, la misma doctrina entiende también que no se pueden deducir consecuencias jurídicas relevantes de la distinción entre las nociones de ciencia, más general, y de "investigación científica y técnica".

En cuanto al contenido de este derecho, lo primero que destaca es la delimitación del objetivo de la promoción. Si bien parece que la ciencia cuenta con la citada presunción de bondad, ni toda actividad científica será objeto de promoción ni ésta se realizará en cualquier dirección. La promoción se centrará en aquella ciencia que se realiza "en beneficio del interés general". Como puede imaginarse, esta funcionalización constitucional de la promoción científica se observa con prudencia desde las posiciones más liberales y escépticas respecto a la pertinencia de la tutela estatal de la libertad de investigación científica. En particular estos enfoques subrayan que la formulación constitucional tiene una fundamentación desarrollista que prejuzga el tipo de conocimiento que debe promocionar el Estado mientras subordina otros $^{98}$. Aunque se trata de una tensión en cierto sentido ineludible, una vez

96 Véase FERNÁNDEZ DE GATTA, “La libertad de creación científica en la evolución de la ciencia y la tecnología”, cit. p. 118 y M. CONTRERAS CASADO, “El fomento de la investigación científica como principio rector constitucional (artículo 44.2 CE) y su articulación en el Estado Autonómico", en R. L. CHUECA (ed.), La investigación científica como derecho fundamental, cit. pp. 130-132., donde se hace referencia a la posición del TC en este sentido.

97 En este sentido, véase por ejemplo SHAVER, “The Right to Science: Ensuring that Everyone Benefits from Scientific and Technological Progress", cit. pp. 415 y 416.

98 Por ejemplo DARNACULLETA, "Libertad de investigación científica y la promoción de la ciencia en beneficio del interés general”, cit. p. 3 atribuye este enfoque desarrollista a la Ley 14/2011 de ciencia y señala que "en pleno siglo XXI, a pesar de las evidentes consecuencias reflexivas del desarrollo tecnológico y de la incertidumbre científica sobre sus efectos, el Derecho parece mantener intacta su fe en las bondades de la ciencia, promoviendo activamente un cientifismo de corte utilitarista que no se corresponde con el ocaso de la modernidad". 
se aceptan las premisas axiológicas y sociológicas de la expansión del Estado Social, conviene que la enmarcación de este debate atienda a algunas precisiones. En primer lugar, al delimitar el objeto ciencia ya se indicó que tal no estaba vinculado a la ausencia de intervención, sino, al contrario, a una constante gubermentalización de la actividad científica y de su comunidad ${ }^{99}$, por lo que el primer paso para adentrarse en esta tensión sería identificar qué normas son las que están definiendo la ciencia "válida", es decir, la que es objeto de promoción. En segundo lugar, parece evidente que no cabe interpretar las referencias al interés general como una subordinación completa de toda acción pública al interés económico o del desarrollo, sino, en conjunto con el resto de principios constitucionales, más bien como una alusión a un sentido integral del beneficio para una mayoría de ciudadanos, algo que debe decidirse mediante los mecanismos democráticos de toma de decisiones y establecimiento de prioridades en la acción pública ${ }^{100}$.

Sentado esto, el siguiente paso es determinar cuáles son los valores con los que resulta legítimo establecer un vínculo en la promoción de la ciencia. El ámbito científico puede contar con una relativa autonomía formal para la definición de sus contornos y, con ello, para la discriminación de los objetos de protección pero no con una completa autonomía axiológica respecto a los valores consagrados en el ordenamiento jurídico. De hecho, el presente artículo ha delimitado algunos de ellos: protección de la libertad de investigación individual y colectiva dentro de un sentido normativizado pero plural de la ciencia, aumento de la cantidad de personas y de la proporción de su participación en el diseño y ejecución de la actividad científica, así como en el disfrute de sus beneficios, con especial atención a la incorporación de las poblaciones más vulnerables. De este modo puede configurarse un marco constitucional a la luz del cual valorar si los desarrollos legislativos y normativos, las políticas públicas, así como las intervenciones concretas de los poderes públicos tienen validez o deben ser descartadas ${ }^{101}$, teniendo en cuenta también que las vulneraciones al derecho de la ciencia no solo proceden de la injerencia pública, sino de manera creciente de la omisión de una acción pública eficaz.

$99 \quad$ Vid. supra sección 2.1.

100 Véase por ejemplo la posición de ARRUEGO, “El derecho fundamental a la investigación científica en la Constitución Española de 1978”, cit. p. 56 en esta dirección.

101 Véase, como un ejemplo de este análisis crítico, a RODRÍGUEZ, "Libertad de investigación científica y sexenios", cit. pp. 235 y ss, en la argumentación que concluye que las normas que establecen los criterios de evaluación previa a la concesión de sexenios para el personal docente e investigador no tienen el rango normativo adecuado. 
Delimitados los márgenes legítimos de la intervención, surge la necesidad de concretar su contenido, ya que tanto la acción de "promover" como la referencia a la "ciencia" resultan bastante amplias. En síntesis, se trata de la obligación de apoyar "actividades directamente conducentes a descubrimientos científicos o a avances técnicos" pero "también la divulgación de los resultados obtenidos" 102 , lo que refuerza la efectividad del derecho de acceso que se analizó en el apartado anterior. La doctrina interesada en la efectividad de los derechos, sobre todo de los clasificados como derechos sociales, ha desgranado esa obligación genérica en un conjunto de aspectos de la acción pública que deben completarse. Se trata de un conjunto heterogéneo ${ }^{103}$, como exige la naturaleza de los principios jurídicos y su implementación en el contexto de la acción legislativa y las políticas públicas ${ }^{104}$.

Los poderes públicos tienen obligación, en primer lugar, de disponer los medios económicos, institucionales, técnicos y humanos oportunos para poder desarrollar, al menos, las actividades de creación y divulgación. En segundo lugar, tienen la obligación de establecer dotaciones presupuestarias suficientes para que tales procesos se completen de manera adecuada. Como en otros ámbitos, esta responsabilidad sobre la financiación y la autonomía sobre su destino depende de la distribución competencial. En el caso de la ciencia, dicha distribución no podría preterir la responsabilidad estatal en la garantía, también mediante acciones positivas, de la libertad de investigación científica del artículo 20.1.b CE ${ }^{105}$. Además, a la distribución Estado - Comunidades Autónomas, se añade aquí la autonomía universitaria (artí-

102 Véase STC 53/1988, FJ 1 y FERNÁNDEZ DE GATTA, “La libertad de creación científica en la evolución de la ciencia y la tecnología", cit. pp. 118 y 119 respecto a la evolución de las posiciones del TC en esta materia.

103 Los contenidos obligacionales que se van a exponer se encuentran con detalle en M. CALVO, "Derechos sociales : algunas propuestas para seguir avanzando en tiempos de incertidumbre", p. 150.

104 Respecto a la noción de implementación, véase M. CALVOGARCÍA, Transformaciones del Estado y del Derecho, Universidad Externado de Colombia, Bogotá, 2005, pp. 12 y ss. En L. PRIETO SANCHÍS, "Diez argumentos a propósito de los principios", Jueces para la democracia, núm. 26, 1996, pp. 41-49. se encuentra asimismo un excelente resumen de las consecuencias de las particularidades de los principios.

105 Véase VELÁZQUEZ, “Ártículo 44”, cit. pp. 845-6 sobre la distribución competencia entre Estado y Comunidades Autónomas en esta materia, conforme al esquema de competencia fundamental sobre el derecho fundamental derivado del artículo 20.1.b) y concurrencia y acumulación de potestades respecto a las obligaciones derivadas del artículo 44.2 de la Constitución, tanto del Estado y las Comunidades autónomas, como de la Unión Europea y la administración local.

ISSN: 1133-0937

DOI: https://doi.org/10.20318/dyl.2021.6110
DERECHOS Y LIBERTADES

Número 45, Época II, junio 2021, pp. 327-364 
culo 27.10 CE), que sin embargo resulta exigua precisamente en cuanto a su dimensión financiera ${ }^{106}$.

En tercer lugar, las obligaciones anteriores no pueden realizarse mediante una simple transferencia dineraria puntual o periódica, sino que la obligación abarca a la creación o a la adaptación de aparatos o de instituciones de intervención públicas o que cuenten con validación pública, a las que se debe incorporar personal experto. El conjunto de estas intervenciones estará sujeto asimismo a un sistema de controles y evaluaciones.

Sin embargo, la delimitación de su contenido normativo no prejuzga la efectividad de este derecho. A este respecto, llama la atención el carácter flexible de las citadas obligaciones en derecho español ${ }^{107}$, debido a su ubicación normativa y a las garantías que esto ofrece ex articulo 53.3 de la misma norma. La mayor parte de la doctrina constitucionalista postula que debe entenderse una escisión de "la faceta libertad, en este caso científica, incluida en el art. 20.1.b CE de la faceta de función prestacional del poder público recogida en el presente art. 44.2 CE." ${ }^{108}$. A consecuencia de esto, su efectividad se remite a un posterior desarrollo legal ${ }^{109}$, que tampoco sería inconstitucio-

106 Desde la perspectiva de M. CUETO, “El régimen jurídico de la investigación en la universidad: novedades de la LOU”, cit., p. 486, la efectividad de la libertad de investigación en un plano individual y de la autonomía universitaria exige un refuerzo de su autonomía financiera: "las Universidades deberían contar con una mayor financiación propia, que asegurase de mejor forma la libertad de Cátedra y el derecho a la producción y creación científica y técnica que reconoce el artículo 20 de la CE, derechos que no pueden verse afectados ni por la autonomía universitaria, ni por las competencias estatales ni autonómicas".

107 Otros ámbitos, como la regulación internacional de la investigación en biodiversidad, podrían servir en cambio de referencia para la configuración de un régimen de derechos más efectivo. Véase MORGERA, "Fair and Equitable Benefit-Sharing at the Cross-Roads of the Human Right to Science and International Biodiversity Law", cit. y A. PLOMER, Patents, Human Rights and Access to Science, Edward Elgar, Broadheath, 2015, entre otros trabajos. Nótese que el foco de vulneración en estos ámbitos es la existencia de una actividad de investigación de la que se excluye a las poblaciones más vulnerables, que además son las que habitan los territorios que contienen esos conocimientos, mientras que, en el caso español, se discute el grado de cumplimiento del Estado de sus obligaciones en la promoción de la investigación.

108 VELÁZQUEZ, “Artículo 44", cit. p. 848. En la misma dirección véase también ARRUEGO, "El derecho fundamental a la investigación científica en la Constitución Española de $1978^{\prime \prime}$, cit., pp. 56 y ss.

109 En el análisis de CONTRERAS, “El fomento de la investigación científica como principio rector constitucional (artículo 44.2 CE) y su articulación en el Estado Autonómico", cit., p. 126 sobre su valor normativo, se resalta que "su reconocimiento y proclamación pertenecen al ámbito constitucional, puesto que son normas constitucionales las que los acogen, pero la 
nal en caso de no atender a esas obligaciones. Si, en cambio, se eleva la mirada al contenido de los Pactos Internacionales y las obligaciones que imponen a los Estados, no existe fundamentación en los mismos para introducir esa discriminación entre la dimensión de libertad y la de promoción. Sí existen particularidades en la forma de cumplimiento de las obligaciones de hacer (pero éstas referidas tanto a la dimensión de libertad como a la de promoción) que imponen una suerte de cumplimiento progresivo ${ }^{110}$. Cabe añadir que una distinción entre distintas dimensiones del derecho puede tener interés desde una perspectiva conceptual o pedagógica; de hecho, el orden del presente artículo se atiene a ella en cierto sentido. También puede ayudar a diseñar con más precisión las garantías de efectividad pertinentes pero no puede ser el rasgo que articule el funcionamiento del derecho a la ciencia ${ }^{111}$.

En primer lugar y desde una perspectiva pragmática, no cabe establecer una distinción tajante entre el par libertades -obligaciones negativas, por una parte, y el par derechos sociales- obligaciones positivas, por otra, porque las confusiones entre ambos son constantes. Por ejemplo, la protección de la libertad de investigación científica exige sostener unas infraestructuras, organizaciones y comunidades que son las que delimitan el propio campo científico, de manera que las actividades de promoción tienen impacto en la eficacia básica de todas las dimensiones del derecho ${ }^{112}$. Tampoco cabe esa distinción rígida desde la perspectiva del control de estas obligaciones, ya que las vulneraciones pueden provenir tanto de la comisión como de la omisión ${ }^{113}$.

efectividad de su ejercicio por parte de los ciudadanos depende necesariamente de lo dispuesto en el ámbito legal, de lo que establezcan, en definitiva, las leyes".

110 Véanse V. ABRAMOVICH y C. COURTIS, Los derechos sociales como derechos exigibles, Trotta, Madrid, 2002 y Á. J. RODRIGO, “Los derechos sociales en tiempos de crisis económica y el desarrollo sostenible", en M. ABAD CASTELOS et al. (eds.), Políticas económicas y derechos sociales, cit. p. 81 y ss.

111 Nótese que no se trata de un rasgo de la cultura jurídica española. En este mismo ámbito, MORGERA, "Fair and Equitable Benefit-Sharing at the Cross-Roads of the Human Right to Science and International Biodiversity Law", cit. y PLOMER, Patents, Human Rights and Access to Science, cit., entre otras referencias, refieren una visión análoga en el contexto internacional.

112 CALVO, "Derechos sociales : algunas propuestas para seguir avanzando en tiempos de incertidumbre", cit. p. 147 y ss muestra cómo también las libertades más básicas exigen para su efectividad una actividad de promoción por parte del Estado, que es una actividad positiva.

113 Se trata de una doctrina consolidada, al menos, desde las Directrices de Maastricht sobre Violaciones a los Derechos Económicos, Sociales y Culturales, de 1997, par. 11. 
En segundo lugar y desde la perspectiva del control de esas obligaciones, a pesar de la dificultad de definir el modo en que los tribunales deberían integrar el derecho ante situaciones de ausencia de desarrollo legal o de un desarrollo ineficaz ${ }^{114}$, la distinción jerárquica entre estas dimensiones debe superarse en favor de una interpretación sistemática de las normas que pivote sobre el contenido del artículo 20.1.b CE y otros principios constitucionales para valorar qué intervenciones de los poderes públicos son necesarias con el objetivo de hacer efectiva la libertad de investigación científica en todas sus dimensiones ${ }^{115}$.

En tercer lugar, los avances en la exigibilidad de todos los derechos ${ }^{116}$ no pueden borrarse a causa de su reinterpretación ${ }^{117}$ en el contexto reciente de austeridad y escasez que rige también respecto a las políticas científicas. La ausencia de norma legal aplicable o la existencia de una política pública materialmente contradictoria con los principios constitucionales en la materia no debería significar, en caso de conflicto, la renuncia a resolver conforme a los principios constitucionales ${ }^{116}$.

Por último, convendría profundizar sobre las implicaciones del sistema axiológico en el que cabe situar el derecho a la ciencia. Al respecto, se han destacado algunos elementos esenciales, como son, primero, el sentido no solo instrumental de este derecho, sino su vínculo con la dignidad y, segundo, la orientación de las intervenciones públicas hacia el interés general, esto es, hacia el sistema de valores propio de un Estado Social y Democrático de Derecho. Separar por completo las cuestiones relativas a la efectividad de la

114 Estas son situaciones que L. FERRAJOLI, Derechos y garantías: la ley del más débil, P. ANDRÉS y A. GREPPI (trads.), Trotta, Madrid, 5a ed., 2006, p. 28 y ss ha calificado como lagunas.

115 Véase CABRERA, “El derecho fundamental a la libertad de investigación científica (art. 20.1. CE) como principio organizativo. El caso de las reales academias", cit., pp. 139-40: "sin embargo, "[n] c cabe excluir que la relación entre alguno de esos principios y los derechos fundamentales (señaladamente el de igualdad) haga posible un examen de este género (cf., por ejemplo, nuestra STC 155/1987), ni, sobre todo, que el principio rector sea utilizado como criterio para resolver sobre la constitucionalidad de una acción positiva del legislador, cuando ésta se plasma en una norma de notable incidencia sobre la entidad constitucionalmente protegida" (STC 45/1989, de 20 de febrero, FJ 4)".

116 De manera analógica, es pertinente la argumentación de la Observación General $n^{\circ}$ 9 del Comité de Derechos Económicos, Sociales y Culturales, en su parágrafo 9 (https://www. escr-net.org/es/recursos/observacion-general-no-9-aplicacion-interna-del-pacto), que señalaba que, si un derecho no puede ejercerse plenamente sin una intervención del Poder Judicial, es necesario establecer los recursos judiciales pertinentes. 
dimensión de libertad del derecho de las relativas a su dimensión promocional contravendría la base material de nuestro ordenamiento porque solo atendería a una noción negativa de la libertad y por ello parcial respecto a la realidad de la creación científica. Una noción, por lo tanto, ajena a las exigencias de sostenibilidad y carácter colectivo e institucional de sus procesos reales. Cabe presumir que una investigación más profunda sobre las vulneraciones concretas de este derecho serviría además para revelar la proliferación de estas conexiones entre los distintos planos del derecho y para diseñar garantías de efectividad que abarquen todos sus aspectos.

\section{CONCLUSIONES}

Al actualizar la mirada sobre el derecho a la ciencia, han cobrado fuerza algunas singularidades que no tenían mayor protagonismo durante su formulación inicial a mitad del siglo XX. En primer lugar, en las sociedades postindustriales esta libertad no se configura sobre todo frente a la acción del Estado, aunque tutelarla frente a sus injerencias forme parte del contenido esencial del derecho, sino a partir de la labor de normación e institucionalización que resulta en buena medida una labor pública. En segundo lugar, esta constatación no estaría completa si no se incluyera el rol de la comunidad científica, en particular en la delimitación del objeto del derecho, la ciencia, y por lo tanto de las actividades susceptibles de tutela y en la gobernanza de las normas e instituciones científicas. Por ello, se ha caracterizado la ciencia como un bien común. En tercer lugar, esto hace que la efectividad de la libertad científica exija tres condiciones acumulativas: 1) la ausencia de injerencias durante todo el proceso de investigación y 2) la creación y sostenimiento de un marco institucional y normativo en el que pudieran definirse, validarse y hacerse valer las formas científicas y 3) la creación y sostenimiento de una comunidad científica que nutra y someta a juicio constante la creación y sostenimiento del marco institucional y normativo al que se aludió en la segunda condición.

En cuarto lugar y al tratar de la dimensión del derecho de acceso en la ciencia, su contenido no puede limitarse al de acceder a los beneficios que produce el conocimiento científico, algo por otra parte esencial, sino que es necesario situar en el primer plano el derecho de participación del conjunto de la ciudadanía, y no solo de la estricta comunidad científica o de los poderes públicos, en el diseño e implementación de la acción científica. Por 
último, se constata que, en la consideración de este derecho, sigue vigente la división y jerarquización entre las libertades y los derechos económicos, sociales y culturales. Este artículo ha mostrado, en cambio, la estrecha interrelación entre la eficacia de la libertad científica más básica y la efectividad de las obligaciones estatales de acción positiva en el aseguramiento de un marco normativo, institucional y presupuestario suficiente. Es necesario asimismo ampliar la investigación empírica sobre cómo las políticas de austeridad sostenidas durante una década en el ámbito científico han dado lugar a vulneraciones que se superponen a las tradicionales de censura o de imposición de una agenda científica. Todo ello es imprescindible para diseñar indicadores fiables en este campo y garantías eficaces del derecho a la ciencia.

\author{
DAVID VILA-VIÑAS \\ Laboratorio de Sociología Jurídica \\ Facultad de Derecho \\ Universidad de Zaragoza \\ c) Pedro Cerbuna, 10 \\ Zaragoza 50010 \\ e-mail:dvila@unizar.es
}

